Subcontractor Report

\title{
Gasification of Refuse Derived Fuel in the Battelle High Throughput Gasification System
}

July1989

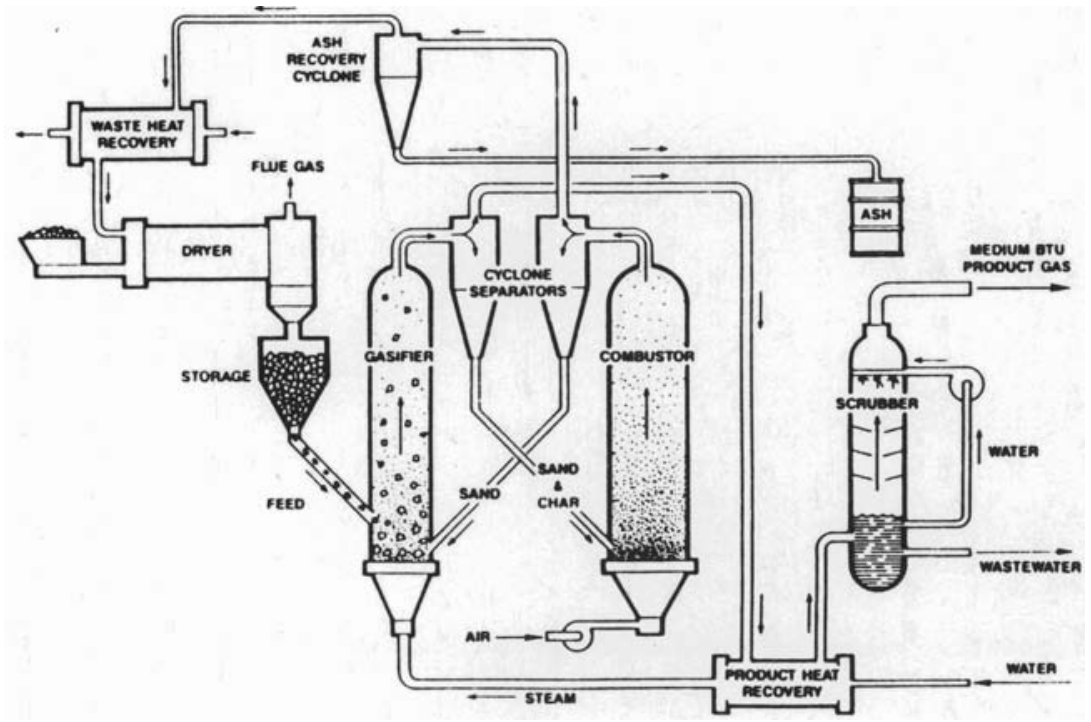

Prepared for the

U.S. Department of Energy

under Contract DE-AC06-76RLO 1830

Pacific Northwest Laboratory

Operated for the U.S. Department of Energy

by Battelle Memorial Institute 


\section{DISCLAIMER}

This program was prepared as an account of work sponsored by an agency of the United States Government. Neither the United States Government nor any agency thereof, nor Battelle Memorial Institute, nor any or their employees, makes any warranty, expressed or implied, or assumes any legal liability or responsibility for the accuracy, completeness, or usefulnessof any information, apparatus, product, or process disclosed, or represents that its use would not infringe privately owned rights. Reference herein to any specific commercial product, process, or service by trade name, trademark, manufacturer, or otherwise, does not necessarily constitute or imply its endorsement, recommendation, or favoring by the United States Government of any agency thereof, or BattelleMemorial Institute. The views and opinions of authors expressed herein do not necessarily state or reflect those of the United States Government or any agency thereof.

\section{PACIFIC NORTHWEST LABORATORY operated by BATTELLE MEMORIAL INSTITUTE for the \\ UNITED STATES DEPARTMENTOF ENERGY under Contract DE-AC06-76RLO 1830}

\section{Printed in the United States of America}

Available to DOE and DOE contractors from the

Office of Scientific and Technical Information, P.O. Box 62, Oak Ridge, TN 37831; prices available from (615)576-8401. FTS 626-8401.

Available to the public from the National Technical Information Service, U.S. Department of Commerce, 5285 Port Royal Rd., Springfield, VA 22161.

NTIS Price Codes, Microfiche A01

$$
\text { Printed Copy }
$$

\begin{tabular}{|c|c|}
\hline Pages & $\begin{array}{l}\text { Price } \\
\text { Codes }\end{array}$ \\
\hline $001-025$ & A02 \\
\hline $026-050$ & A03 \\
\hline 051-075 & A04 \\
\hline 076-100 & A05 \\
\hline $101-125$ & A06 \\
\hline $126-150$ & A07 \\
\hline $151-175$ & A08 \\
\hline $176-200$ & A09 \\
\hline $201-225$ & A10 \\
\hline $226-250$ & All \\
\hline $251-275$ & A12 \\
\hline $276-300$ & $\mathrm{~A} 13$ \\
\hline
\end{tabular}


PNL-6998

UC-245

GASIFICATION OF REFUSE DERIVED

FUEL I N THE BATTELLE HIGH

THROUGHPUT GASIFICATION SYSTEM
M. A. Paisley
K. S. Creamer
T. L. Tewksbury
D. R. Taylor

Battelle Columbus Division

Columbus, Ohio

G. F. Schiefelbein, PNL Project Manager

July 1989

Prepared by Battelle Columbus Division

for Pacific Northwest Laboratory

under Contract DE-AC06-76RLO 1830

with the U.S. Department of Energy

under Agreement 007069-A-H6

Pacific Northwest Laboratory

Richland, Washington 99352 



\section{EXECUTIVE SUMMARY}

Battel le has conducted a testing program to evaluate the application of its High-Throughput Gasification Process to non-wood biomass fuels. The feedstock chosen for this study was a prepared municipal solid waste, Refuse Derived Fuel (RDF) .

The successful application of gasification as a disposal method has advantages over state-of-the-art approaches such as land filling or mass burn technology. A more readily usable form of energy is produced and at a cost significantly lower than mass burn technology.

\section{Experimental Program}

The experimental results discussed in this report demonstrate the similarity of RDF, as a gasification feedstock, to wood. The Battelle Gasification Process has been extensively tested with wood and this data base then can be confidentially applied to RDF gasification. In the two-stage Battel le process, RDF is gasified to a medium Btu gas (500-550 Btu/scf) without oxygen in a high-throughput gasifier and residual char is consumed in an associated combustor. A circulating sand phase provides heat transfer between the separate reactors.

The process is environmentally simple with gaseous emissions from the combustor being well within new source performance standards. Waste water from the process contains only trace quantities of organic materials. The outlet of a simple industrial treatment system at Battelle's PRU site showed waste water to be within EPA's drinking water standards. This treatment consisted of a sand filter followed by a simple charcoal filter.

\section{Process Economics}

A preliminary economic evaluation was made to compare the performance of the Battelle process to mass burn technology. The throughputs possible in the Battelle gasification process (over $2000 \mathrm{lb} / \mathrm{hr}-\mathrm{ft}^{2}$ ) result in extremely compact reactor vessels. Capital costs are thus greatly reduced providing capital advantages over mass burn technology. A 2000 TPD RDF 
gasification plant is projected to cost $\$ 89$ million compared to $\$ 170$ million for a similarly sized mass burn facility. Both cost estimates assume electric power is the prime product from the plant and so include the costs of turbines necessary for power production.

The gasification plant will produce more power per unit of RDF-fired than will a similarly sized mass burn plant. For the same 2000 TPD plant size, $60 \mathrm{MW}$ would be produced from the mass burn facility while 112 MW would be produced by gasification. This dramatic difference is possible because of the higher thermal efficiencies of gas combustion turbines over steam turbines.

These economics show that the Battel le Gasification Technology can compete favorably with mass burn technology in the marketplace both in terms of capital cost and in quantity of power produced. The program described in this report provides data on the Battelle process that demonstrates the following benefits to users of the technology.

- High throughputs resulting in reduced capital costs

- Low capital and operating costs through elimination of oxygen in the gasifier

- High energy density product gas providing ready application in existing combustion equipment

- Low by product production resulting in simple environmental control systems. 


\section{CONTENTS}

Page

EXECUTIVE SUMMARY ..................... i i i

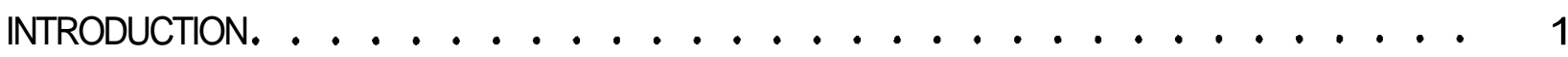
BACKGROUND. . . . . . . . . . . . . . . . . 2 PROCESS DESCRIPTION .................. 5

The Basic Concept.............. 5

Application of the Technology to RDF......... 5

Anticipated Cost Advantages ............. 6

Gasification Character. ........... 6

EXPERIMENTAL PROGRAM. ................. 7

Experimental Equipment. ............ 7

DATAACQUISITIONANDANALYSIS . . . . . . . . . . . . 17

Experimental Procedure. . . . . . . . . . 18

RESULTS AND DISCUSSION. . . . . . . . . . 19

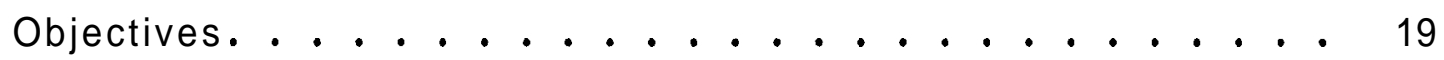

RDF Selection................. 19

Shakedown Testing. . . . . . . . . . . . . 20

Testing and Data Acquisition ........... 22

Gasifier Temperature ................ 22

Product Gas Heating Value. . . . . . . . . . . . 24

Wastewater. . . . . . . . . . . 28

Tar Production ............... 29

Gasifier Throughput. . . . . . . . . . . 29

PROJECTED PROCESS ECONOMICS . . . . . . . . . . . . . 29

CONCLUSIONS AND RECOMMENDATIONS . . . . . . . . . . . . 32

REFERENCES. . . . . . . . . . . . . . . . . . 33

APPENDIX A - WASTE WATtR EFFLUENT ANALYSES. . . . . . . . . A.1

APPENDIX B - SAMPLE CALCULATIONS AND STATISTICAL ANALYSIS . . . . . . B.I 


\section{$\underline{\text { TABLES }}$}

$\underline{\text { Page }}$

Table 1. Features/Benefits of the Battelle High Throughput Gasification Process....................... 4

Table 2. Comparison of Wood and RDF Analyses. . . . . . . . . . . . . 6

Table 3. RDF Gasification Run Results - 10 Inch Gasifier. . . . . . . 23

Table 4. RDF Chemical Analyses. . . . . . . . . . . 26

Table 5. RDF Ash Analytical Results . . . . . . . . . . . 26

Table 6. Typical RDF Derived Product Gas Analysis . . . . . . . . 28

Table 7. .Economic Comparison RDF Gasification Versus Mass Burn. . . . . 30

\section{FIGURES}

Figure 1. Battelle's Biomass Gasification System . . . . . . . . 3

Figure 2. Battelle's Biomass Gasification PRU . . . . . . . . 8

Figure 3. Battel le's Biomass Gasification PRU . . . . . . . . . . . . . 9

Figure 4. Photograph Showing Overhead View of Air and Gas Distributors. 11

Figure 5. Detailed Sketch of Combustor Vessel. . . . . . . . . . 12

Figure 6. Base of Battelle Gasifier . . . . . . . . . . . 14

Figure 7. L-Valve System. . . . . . . . . . . . . . 15

Figure 8. Wood Feed System. . . . . . . . . . . . . 16

Figure 9. Conversion vs Temperature . . . . . . . . . . . 21

Figure 10. Conversion vs Temperature . . . . . . . . . . . 25

Figure 11. Heating Value vs Feed Rate. . . . . . . . . . . . . . . . . . 27

Figure 12. Mass and Energy Balance Summary . . . . . . . . . . . . . . . 31 
FINAL REPORT

on

GASIFICATION OF REFUSE DERIVED FUEL IN THE

BATTELLE HIGH THROUGHPUT GASIFICATION SYSTEM

\section{INTRODUCTION}

This report presents the results of an experimental program to demonstrate the suitability of the Battelle High Throughput Gasification Process to non-wood biomass fuels. An extensive data base on wood gasification was generated during a multi-year experimental program. This data base and subsequent design and economic analysis activities led to the discussion to study the gasification character of other fuels. The specific fuel studied was refuse derived fuel (RDF) which is a prepared municipal sol id waste (MSW). The use of RDF, while providing a valuable fuel, can also provide a solution to MSW disposal problems.

The disposal of MSW is becoming an increasingly serious problem throughout the United States. With MSW generation rates of 5 to 10 lbs/person/day even modest sized cities have a serious disposal problems. (1) Sites available for landfills are scarce and environmental regulations and other siting requirements further limit available land. Various research and commercial scale programs have been conducted to develop improved methods for disposal of these materials.

Gasification of MSW provides advantages over land fill or mass burn technology since a more usable form of energy, medium Btu gas, is produced. Land filling of wastes produces no usable products and mass burning while greatly reducing the volume of wastes for disposal can produce only steam. This steam must be used on site or very nearby thus limiting the potential locations for mass burn facilities. Such a gas, if produced from currently available supplies of MSW, can contribute 2 quads to the U.S. energy supply. 


\section{BACKGROUND}

Development efforts on the Battelle High Throughput Gasification Process were initiated in 1977. Detailed process development activities were initiated in 1980 with the construction and start-up of a process research unit (PRU) at Battelle's West Jefferson Laboratory. These PRU investigations, conducted during the mid-1980s demonstrated the technical feasibility of the gasification process and provided the basis for a detailed process conceptual design to be generated.

The PRU design was such that the inherently high reactivity of biomass feedstocks could be exploited. Conventional reactor systems, i.e., fixed bed and bubbling fluid bed gasification processes could not provide sufficient throughput of the biomass materials to take advantage of the biomass reactivity.

The Battelle process employs a circulating fluid bed gasifier to provide sufficiently high throughputs of biomass material. Heat necessary for the gasification reactions is provided from a stream of circulating sand which passes between the gasifier and an associated combustion reactor. The process is shown schematically in Figure 1. A small amount of char is produced as a result of the gasification reactions (typically 20 percent of the feed material). This char provides the fuel for the combustor to reheat the circulating sand. The combustor like the gasifier is a circulating fluid bed reactor and also is capable of high throughputs.

Experimental data were generated in the PRU in gasifiers of 6 in. diameter and $10 \mathrm{in}$. diameter. Data from these two reactors showed that extremely high throughputs (over $4000 \mathrm{lb} / \mathrm{hr}-\mathrm{ft}^{2}$ ) could be achieved. A wide range of feed materials has been tested in the system including:

- Hardwood and Softwood Chips

- $\quad$ Shredded Bark

- Sawdust

- Whole Tree Chips

- Shredded Stump Material 


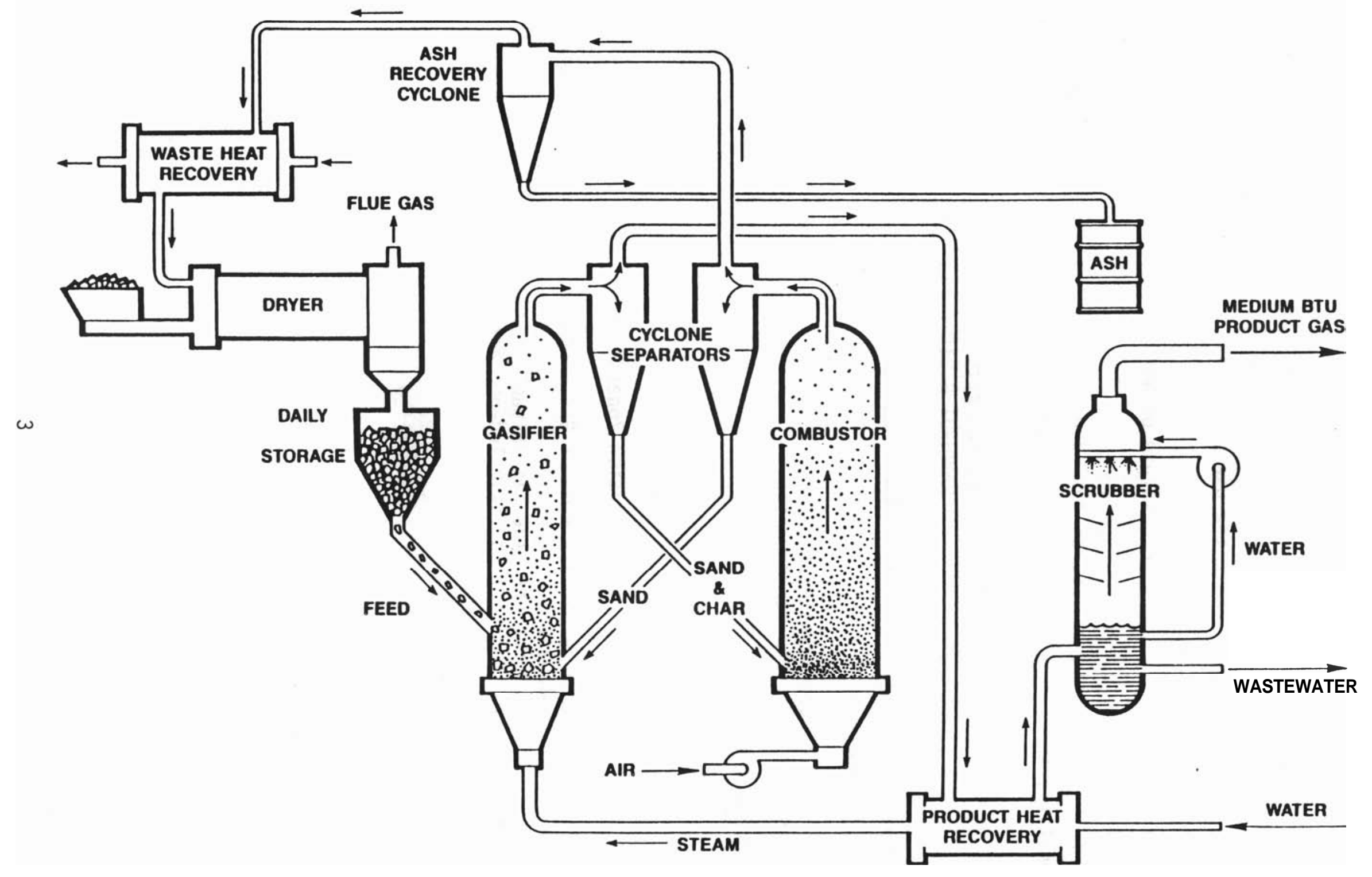

FIGURE 1. BATTELLE'S BIOHASS GASIFICATION SYSTEM 
These tests demonstrated the flexibility of the system to handle a variety of diomass forms with little or no preparation. This flexibility in feedstock acceptance led to the use of RDF as a feedstock for the process.

As an additional process benefit, the product gas heating value was consistent regardless of the moisture or ash content of the feed material tested.

The Battelle process was found to have the following important benefits, shown in Table 1, when compared to other available technologies.

\section{TABLE 1. FEATURES/BENEFITS OF THE BATTELLE HIGH} THROUGHPUT GASIFICATION PROCESS

High Throughput

- $\quad$ Reduced Investment

- Modularized Construction

No Oxygen Plant Required

- $\quad$ Low Operating Costs

- Reduced Plant Investment

Separation of Gasification/Combustion Zones

- High Energy Density Product Gas -- Directly Substitutes for Oil or Natural Gas

- High Temperature Flue Gas Valuable for Heat Recovery

- Product Gas Heating Valve Independent of Feed Moisture

№ Significant Byproduct Production

- Process/Environmental Simplicity

Ability to Handle Wide Range of Feedstocks Without Preparation

- Minimized Feed Costs

- Increased Flexibility 


\section{RROCESS DESCRIPTION}

\section{The Basic Concept}

The Battelle biomass gasification process produces a medium-Btu product gas without the need for an oxygen plant. The process schematic in Figure 1 shows the two reactors and their integration into the overall gasification process. This process uses two physically separate reactors: (1) a gasification reactor in which the biomass is converted into a medium Btu gas and residual char and (2) a combustion reactor that burns the residual char to provide heat for gasification. Heat transfer between reactors is accomplished by circulating sand between the gasifier and the combustor.

The Battelle Process provides a cooled, clean, 450-500 Btu/scf product gas with wood as the feedstock. Waste heat in the flue gas from the combustor can be used to preheat incoming air and then to dry the incoming feedstock. Although these unit operations are not required, they provide a means of increasing product yield by returning waste heat to the process. The condensed organic phase scrubbed from the product gas is separated from the water, in which it is insoluble, and injected into the combustor. As Figure 1 indicates, the products from the process are the cooled cleaned product gas, ash, and treated wastewater.

The flexibility of the process and the potential improvements in economics compared to conventional methods of disposal led to the initiation of the current program.

\section{Application of the Technology to RDF}

Table 2 shows the chemical similarity of wood and RDF. The analysis shown is a typical analysis for RDF produced by National Ecology in Baltimore, Maryland. This same RDF has been used during the PRU tests described below. The chemical similarity of the two materials suggested that RDF might behave in a similar manner to wood in the Battelle process. The PRU tests conducted during the current program verified this expectation and so demonstrated the 
TABLE 2. COMPARISON OF WOOD AND RDF ANALYSES

\begin{tabular}{lrc}
\hline & \multicolumn{2}{c}{ \% Dry Basis } \\
\cline { 2 - 4 } & Wood & RDF \\
\hline Vol ati le Matter & 83.89 & 77.76 \\
Fixed Carbon & 15.78 & 11.23 \\
Ash & 0.33 & 11.01 \\
C & 52.37 & 47.31 \\
H & 6.04 & 6.16 \\
N & 0.02 & 0.68 \\
S & 40.97 & 34.70 \\
C1 & 0.25 & 0.14 \\
Btu & 0.02 & -- \\
& 8739 & 8082 \\
\hline \hline
\end{tabular}

potential of the process to provide an economical alternative to current RDF disposal methods.

The medium Btu gas generated can be readily used in conventional natural gas fired combustion equipment. Examples of potential users of the gas are: steam boilers, gas turbines, industrial heat treating furnaces, and process heaters.

\section{Anticipated Cost Advantages}

For power generation, the lower capital costs combined with the increased power generation efficiency of a combined cycle make the Battelle gasification system especially attractive. Since the final energy product of most waste-to-energy plants is electricity, applying Battelle gasification technology to RDF is a logical extension of its development and demonstration for biomass applications. A more detailed discussion of projected costs is found below.

\section{Gasification Character}

A preliminary test was run in a scaled down version of the PRU. Although not directly a part of this program, this test showed that the 
conversion of RDF corresponded directly to conversion levels measured with wood.

\section{EXPERIMENTAL PROCRAM}

\section{Experimental Equipment}

The RDF test described above was conducted in a continuous 2 in. entrained gasifier. This test indicated that the $2 \mathrm{in}$. unit could be used to screen various types of RDF. However, to generate process scale-up data and to process sufficient RDF to reveal any product shifts due to heterogeneity of the RDF requires testing in the larger capacity biomass gasification PRU. A schematic of this facility is shown in Figure 2. The PRU integrates all the critical unit operations required to convert RDF to a medium-Btu gas including:

- Automated transport of the RDF from storage to a lock hopper feeder system.

- Continuously monitored feeding of the RDF into the gasifier.

- RDF gasification with continuous transfer of circulating solids and char into the gasifier.

- RDF char combustion with circulation of hot solids back to the gasifier controlled by an L-valve.

Scrubbing of medium-Btu product gas and continuous analytical monitoring of the product gas composition.

The PRU used throughout the project is described in detail below. This equipment is shown schematically in Figure 2 and Figure 3 is a photograph of the system.

The combustor is a 40 in. internal diameter fluidized-bed with an active height of $11.5 \mathrm{ft}$. This unit is a refractory-lined vessel with a total refractory thickness of $7 \mathrm{in}$. The refractory lining consists of a $4 \mathrm{in}$. cast inner lining surrounded by $3 \mathrm{in}$. of board insulation. The lining is designed to allow a metal vessel shell temperature of approximately $240 \mathrm{~F}$ to minimize 


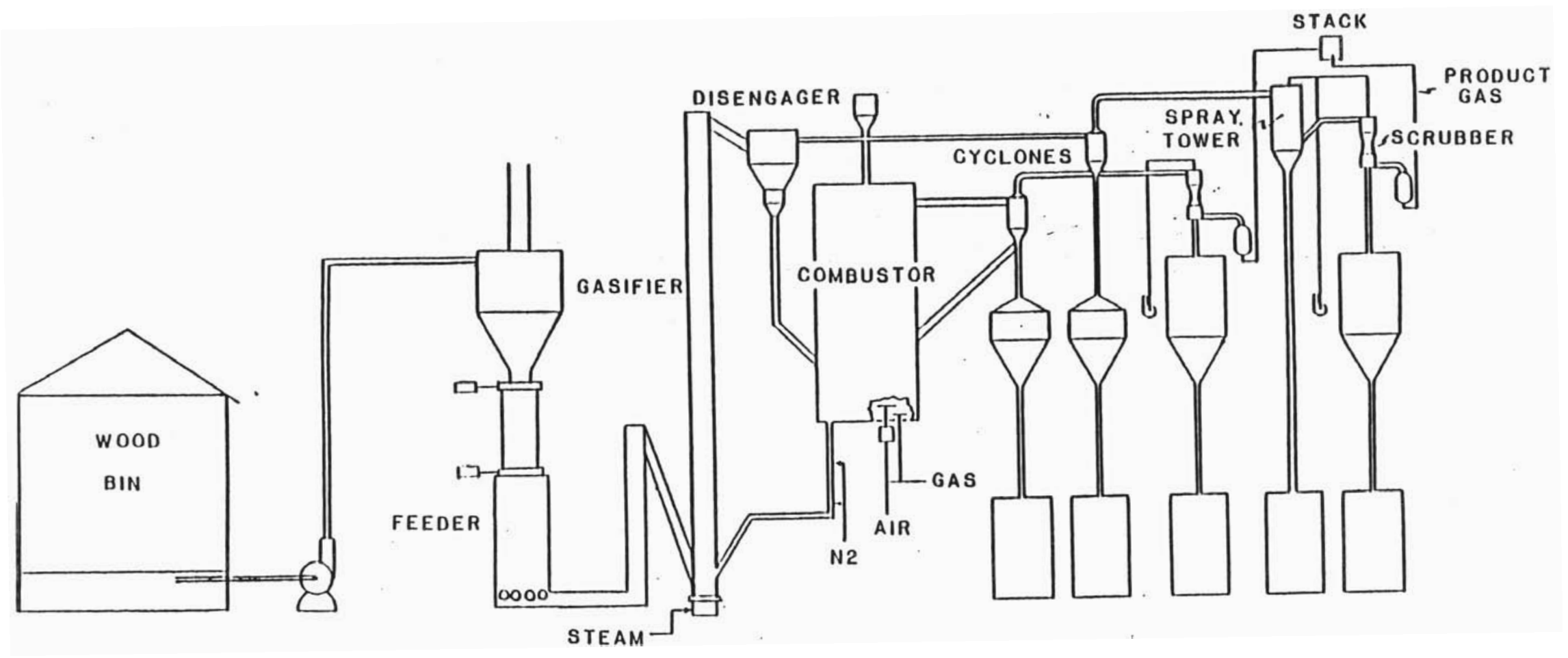

FIGURE 2. BATTELLE'S BIOMASS GASIFICATION PRU 


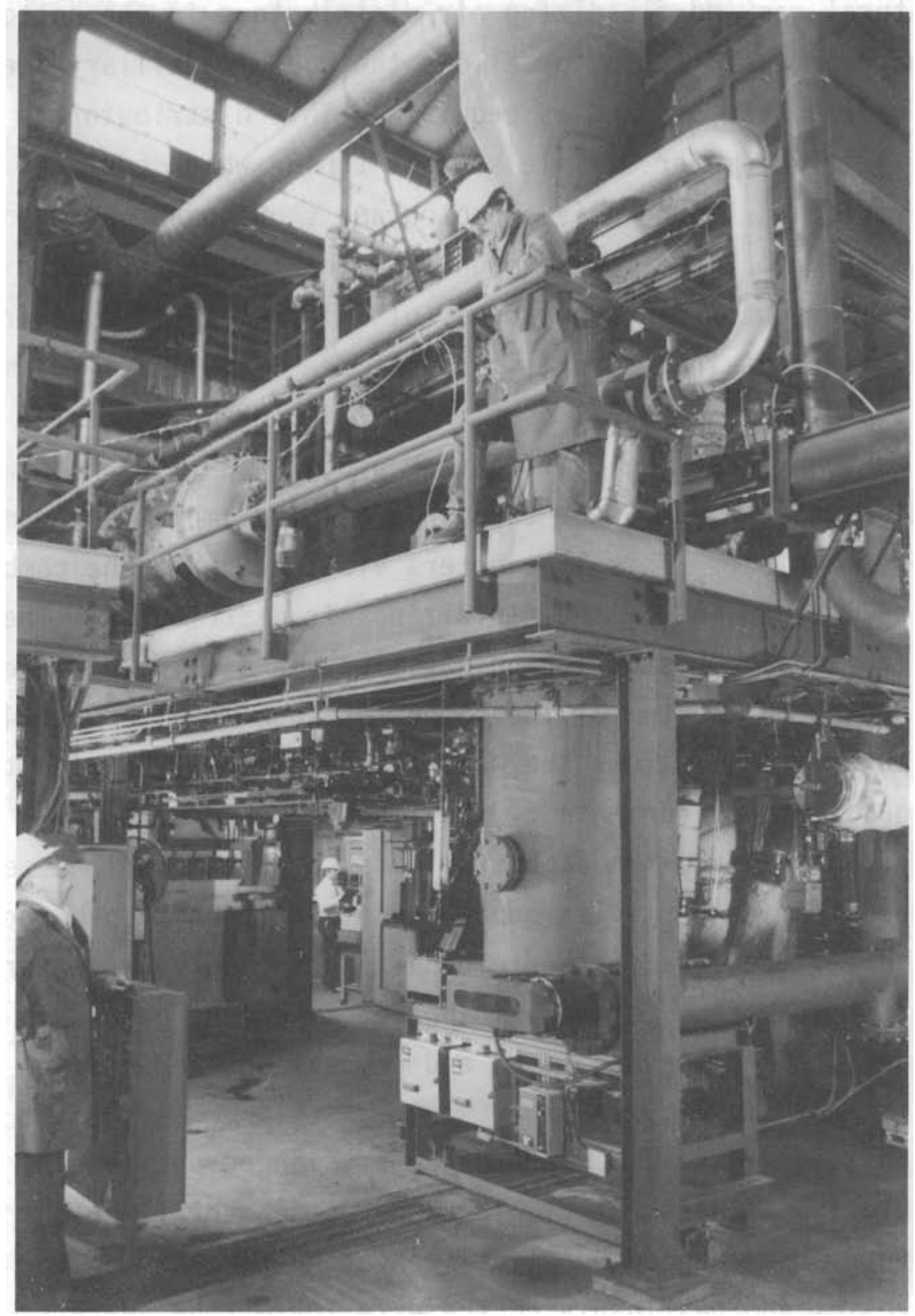

FIGURE 3. BATTELLE'S BIOMASS GASIFICATION PRU 
heat losses. The combustor is instrumented with a number of thermocouples and pressure taps around the perimeter of the vessel at various levels to allow both temperature and pressure monitoring. It is heated initially, during start up, by the use of a natural gas fired start-up burner. The combustor is fitted with natural gas and fluidizing air distributors in the bottom of the vessel. The natural gas distributor allows the use of auxiliary fuel for heating the fluidized bed of sand as required. This distributor is constructed of $\frac{1}{2}-i n$. diameter stainless steel tubing which contains 40-7/64in. diameter orifices. Figure 4 is a photograph showing an overhead view of the air and gas distributors looking down from the top of the combustor. The fluidizing air distributor was constructed of 1-in. diameter pipe from a 3-in. diameter header and contained 60 orifices that are 0.149 in. in diameter. Each orifice is protected by a $2 / 3$ section of $\frac{1}{2}-i n$. diameter tubing welded over the orifice to prevent the orifice from plugging during shutdown.

Sand enters the combustor through a 6-in. diameter downcomer line from the gasifier cyclone. This line enters via the top of the combustor and extends down to within 8 in. of the fluidizing air distributor. The sand bed is circulated from the combustor to the gasifier via a 4-in. diameter L-valve which enters through the bottom of the combustor to a level about 24 in. above the air distributor. This allows the monitoring of a seal between the combustor and gasifier environments by the fluidized bed of sand.

Exhaust gases from the combustor pass through a cyclone separator which discharges the fine particles separated directly back into the fluidized bed. The flue gases then are further cleaned and cooled by a venturi-type scrubber prior to exhausting to the atmosphere. The flue gases are continuously monitored for oxygen level and combustion products. A sketch of the combustor is shown in Figure 5.

The gasifier vessel is constructed of flanged sections of 10-in. diameter Schedule 40 stainless steel pipe and has an overall height of 22.7 $\mathrm{ft}$. The gasifier is surrounded by electric heating elements of the entire length of the vessel and has insulated the exterior of the heaters with about 2 in. of ceramic fiber insulation to prevent heat losses. Fluidizing gases enter the gasifier through a plenum arrangement at the bottom of the gasifier at a level below the RDF feed entry post and the L-valve sand recycle entry 


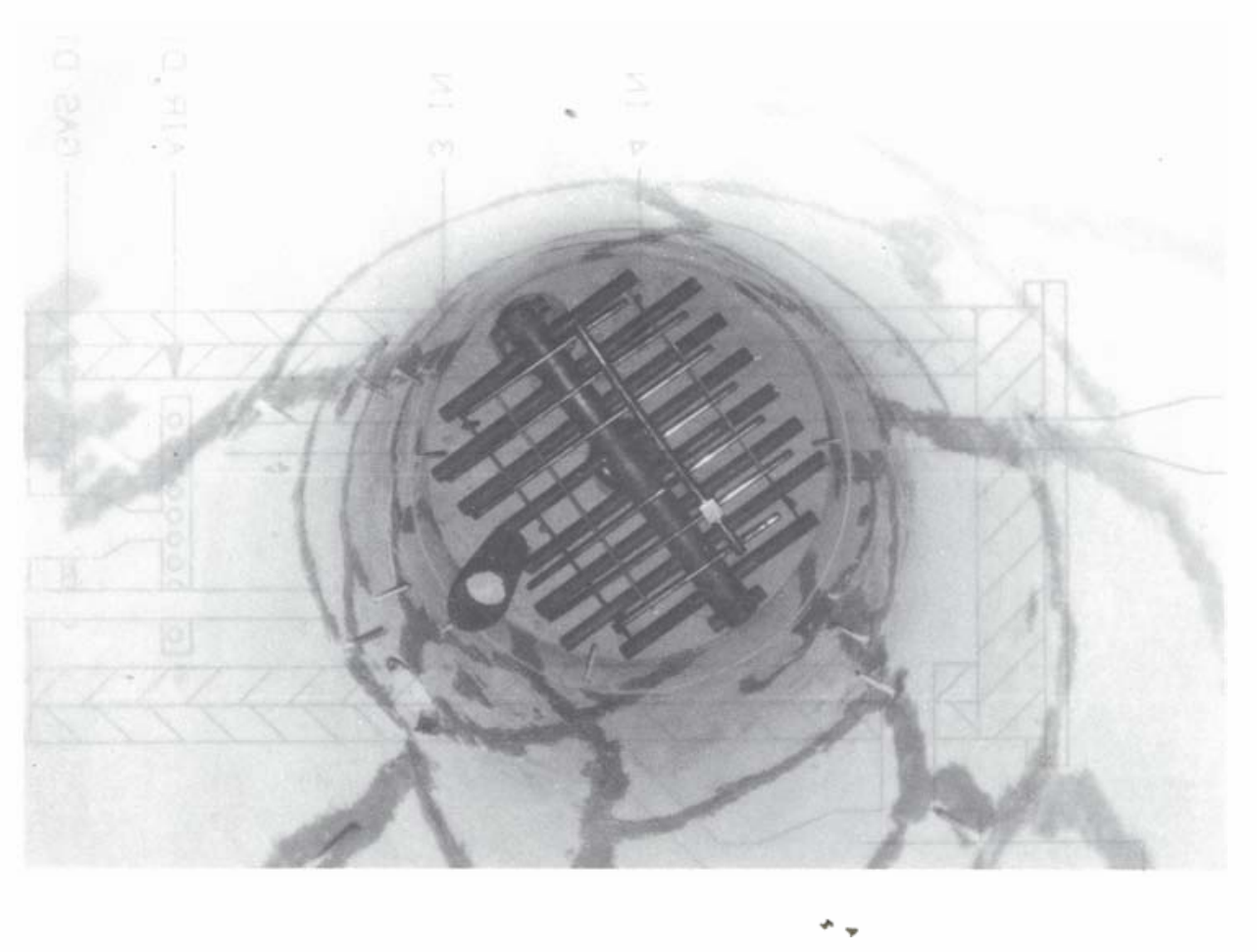

FIGURE 4. PHOTOGRAPH SHOWING OVERHEAD VIEW OF AIR AND GAS DISTRIBUTORS 


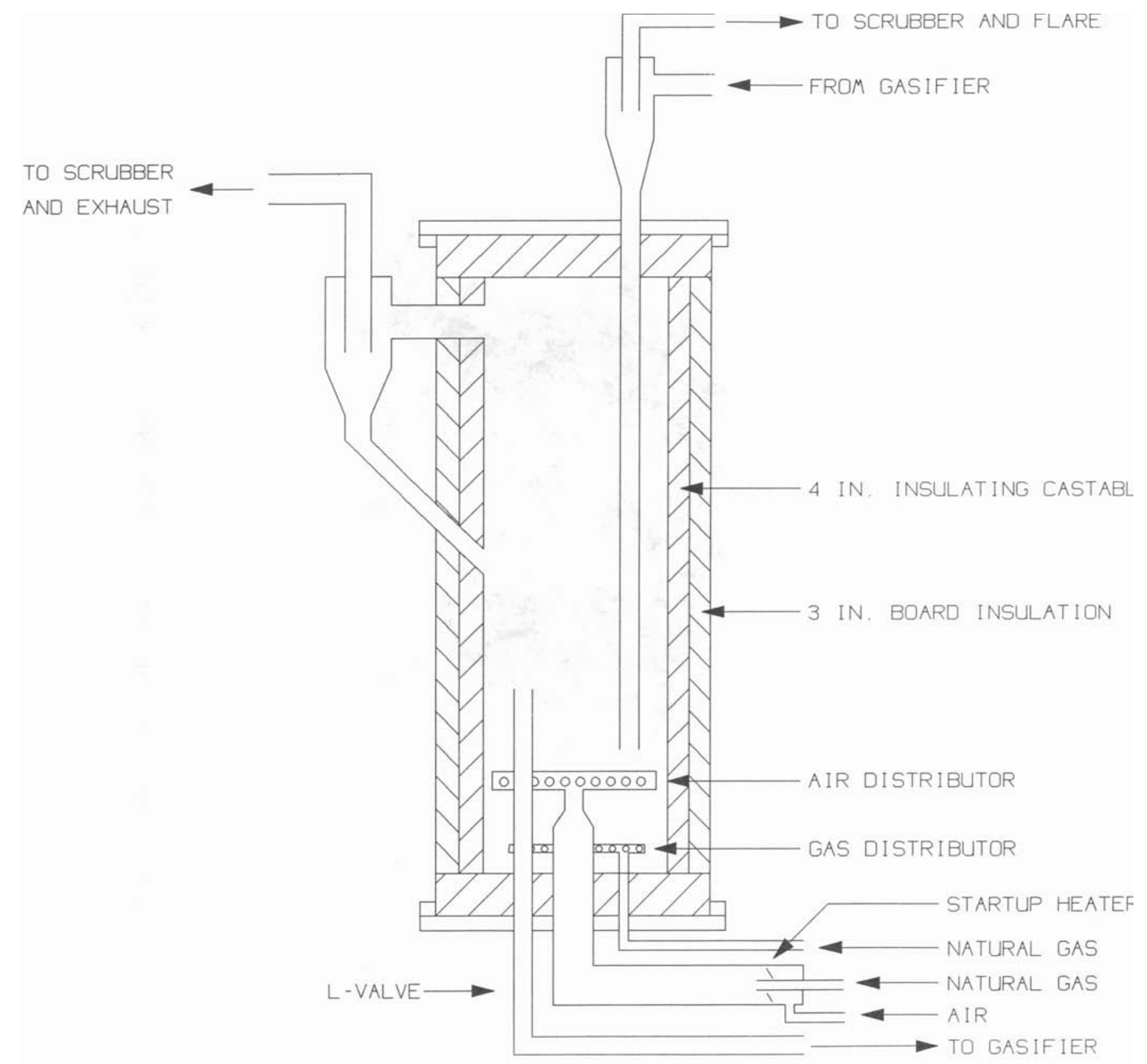

FIGURE 5. DETAILED SKETCH OF COMBUSTOR VESSEL 
point. The sketch in Figure 6 shows the base of the gasifier. The gasifier vessel is fitted with 12 temperature measurement locations and 13 pressure taps.

The sand, char and product gas are conveyed out of the top of the gasifier into the cyclone mounted on top of the combustor which disengages the sand and char and allows them to flow back into the combustor by gravity via the 6 in. downcomer. After separation of the sand and char in the cyclone, the product gas passes through an additional cyclone and is then cooled in a spray tower. A sample of the product gas is analyzed for composition and the remainder is burned in a flare.

Hot sand circulation between the combustor and gasifier is accomplished by a conventional L-valve. The L-valve utilizes a low flow of gas to aerate solids thus allowing flow. Figure 7 is a sketch of the L-valve used. It is constructed of 4-in. diameter stainless steel pipe and is insulated on the exterior with ceramic fiber insulation. Sand circulation ratios were controlled by varying the flow of gas introduced into the vertical leg of the L-valve. There is no direct measurement of solid flow rates through the L-valve but the solids flow through the valve is adjusted to provide the desired temperature difference between the gasifier and combustor. Thus, the gasifier temperature and the temperature differential between vessels are parameters of concern and not circulation rate.

Figure 8 shows schematically the feed system utilized for introducing the shredded RDF into the gasifier. The system consisted of a 15$\mathrm{ft}$ diameter storage silo from which the RDF is transported using a screw auger mounted so as to feed from the center of the floor of the silo. The auger feeds into a $10 \mathrm{HP}$ blower which pneumatically transports the RDF into a lock hopper assembly which is mounted on load cells to provide a constant recording of the hopper assembly plus the contained RDF. The metering bin of the lock hopper system is mounted directly over four 4-in. metering augers which carry the RDF into a 9-in. horizontal auger which empties into the bottom of a 9-in. vertical auger. From the top of the vertical auger the RDE falls, by gravity, down a 6 -in. diameter pipe at 20 degrees from vertical into the bottom of the gasifier. At the bottom of the gasifier the RDF contacts the incoming hot sand and the RDF/sand suspension is transported up the height of the gasifier. 


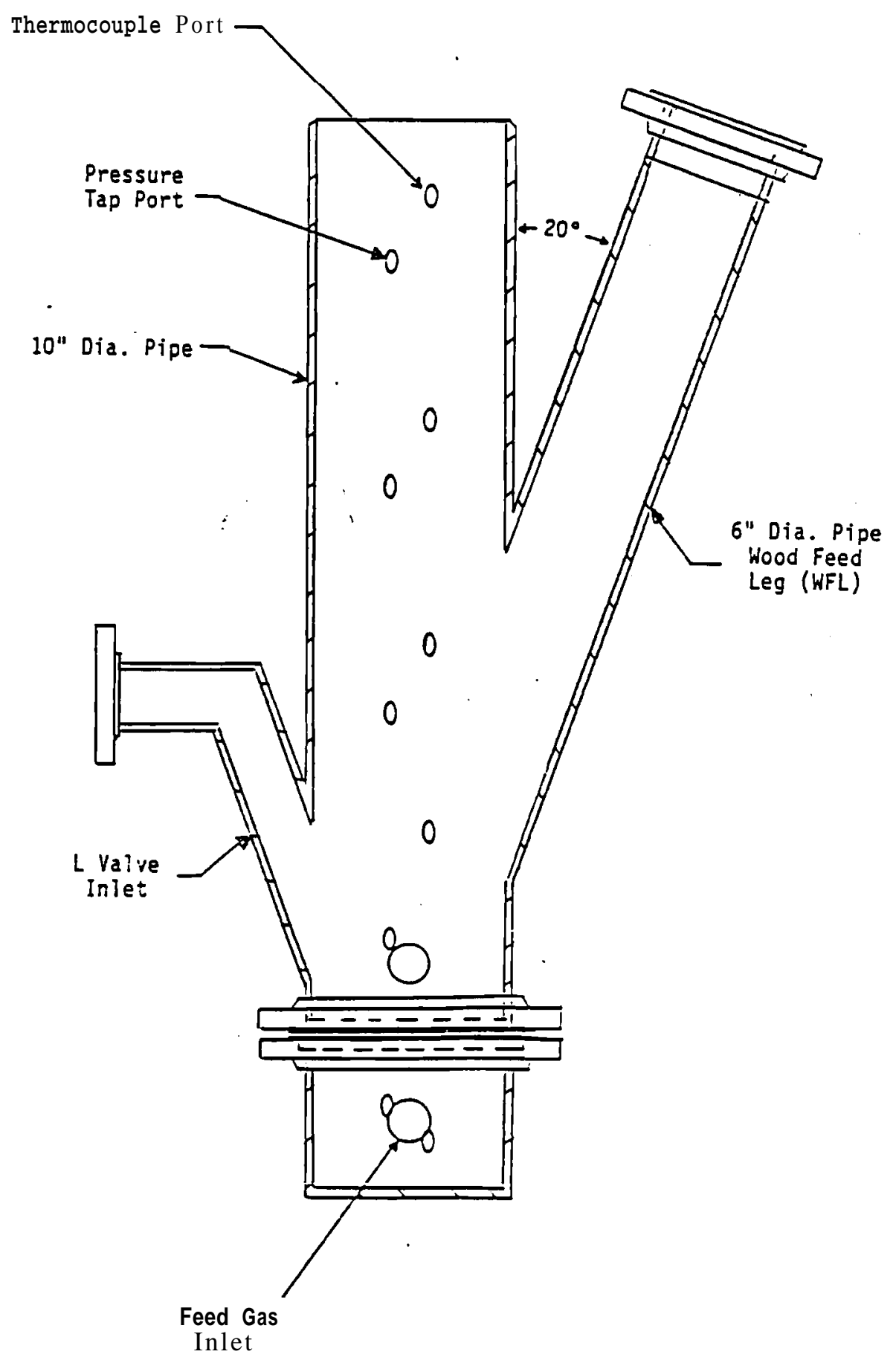

FIGURE 6. BASE OF BATTELLE GASIFIER 


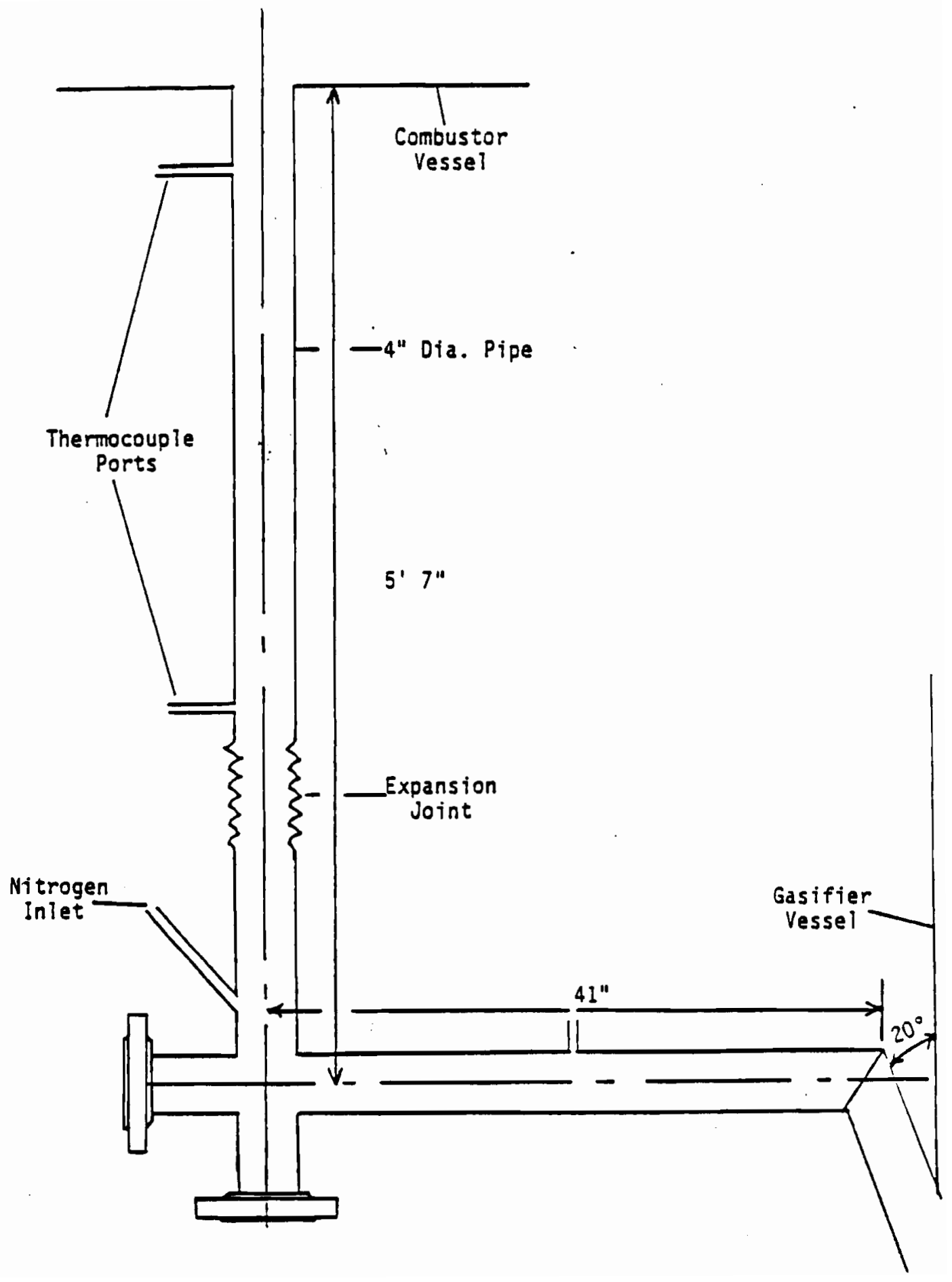

FIGURE 7. L-VALVE SYSTEM 


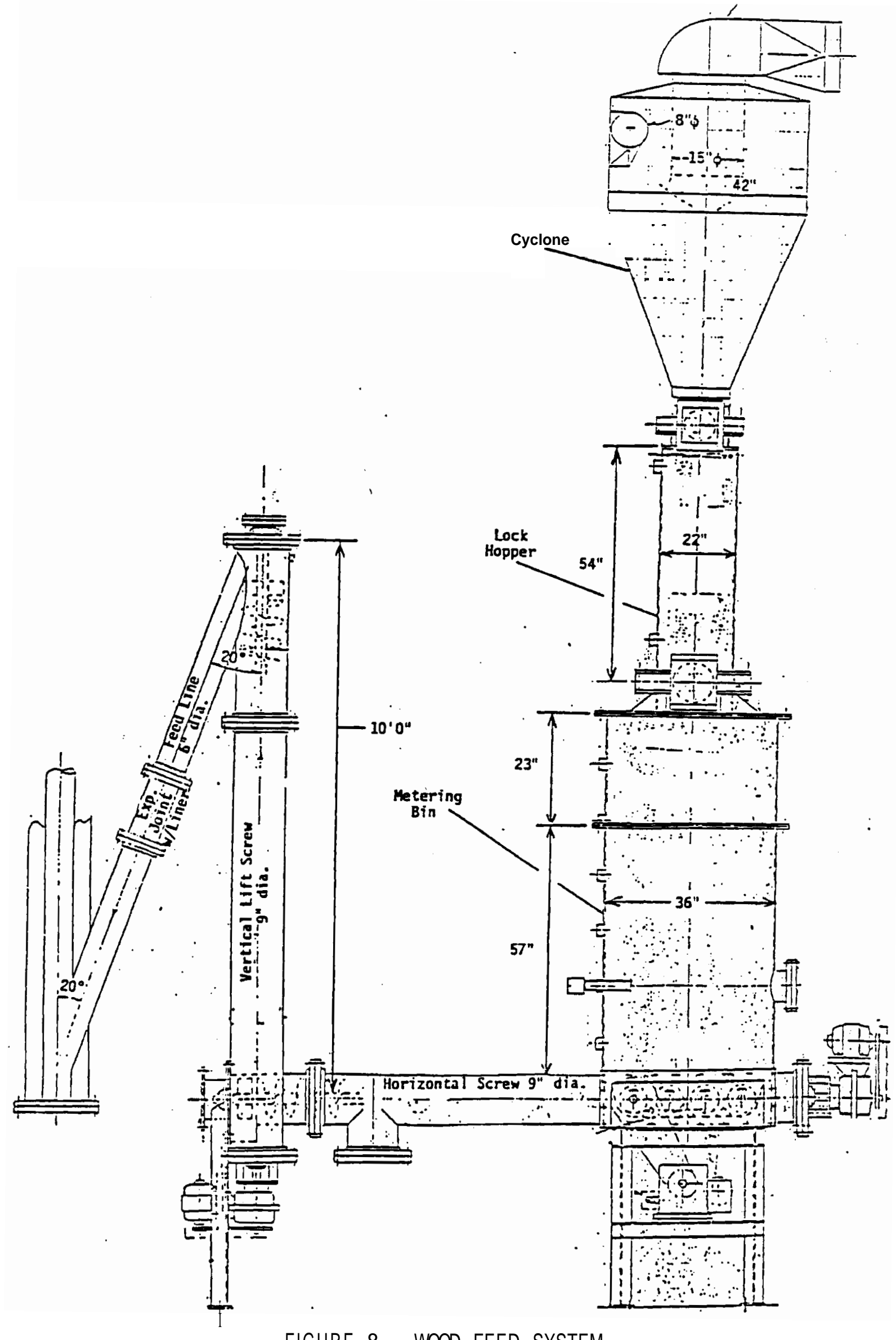

FIGURE 8. WOOD FEED SYSTEM 
The transport of RDF to the hopper assembly, charging of hoppers, pressurizing of hoppers, valve operation and auger operation are automatically controlled electronically by level sensing probes in the hoppers. The lock hopper cycle time is approximately 2 minutes.

The pilot-scale experimental equipment is totally instrumented throughout the system to allow measurement of temperatures, pressures, pressure differentials, flow of air, nitrogen, steam, natural gas and RDF as well as flue and product gas composition. Pressure is measured at over 30 locations throughout the system and temperatures are measured at about 60 locations. Gas, steam and air flows are measured using conventional orifice plates and the orifice AP is continually recorded on strip chart recorders as are the temperatures and pressures. A computerized data acquisition system also collects the process data and stores it on floppy disk. The product and flue gases are sampled and analyzed continuously. Infrared analysis for methane and carbon monoxide in the product gas is utilized while Beckman paramagnetic oxygen analyzers monitor the flue gas. Analyses of the product gas is accomplished every 20 minutes using a gas chromatograph.

\section{DATA ACQUISITION AND ANALYSIS}

The core of the data acquisition system is an BM compatible personal computer and a Hewlett-Packard HP3497A data acquisition and control unit. The computer is equipped with an HPIB interface card to allow communication with the HP3497A. A set of BASIC subroutines supplied by Hewlett Packard were used to simplify these communications. Plug in modules are used in conjunction with the HP3497A to allow measurement of specific functions, in this case thermocouples and voltages.

All system temperatures are measured with Type "K" thermocouples.

System pressures and differential pressures are measured with pressure transmitters with a 4-20 $\mathrm{mA}$ output. These current signals were converted to a 1-5 V signal so they could be read by the HP3497A. The product gas composition is recorded directly by the computer through the computer's serial port from the gas chromatograph.

Oxygen content in the flue gas is also monitored by the HP3497A. 
RDF feed rate, moisture content, heating value, carbon content and certain other parameters must be entered by the user and can be updated at any time during operation.

A BASIC program was written to allow monitoring and storage of system parameters. Raw measurements from the HP3497A are first converted to their respective system temperatures and pressures (and flue gas oxygen content). These temperatures and pressures are then used to calculate system flows. These data are then used in conjunction with the product gas composition to calculate performance parameters such as product gas flow, product gas heating value, cold gas efficiency, carbon conversion, and a carbon balance for the system.

\section{$\underline{\text { Experimental Procedure }}$}

The normal operating procedure used during the project was to preheat the sand bed in the combustor prior to making a run. Approximately $2 \frac{1}{2}$ tons of sand ( $4 \mathrm{ft}$ deep bed) is added to the combustor and the sand is preheated using the natural gas fired start-up burner. After the sand bed reached about $800 \mathrm{~F}$ and fluidization is established, sand circulation via the L-valve was also established for a short period of time ( 1 hr) to heat this part of the system and remove any moisture introduced from the burning of natural gas. The system was allowed to heat overnight with the start-up burner maintained at 1500 to $1600 \mathrm{~F}$. Flue gas and product gas scrubbers are also operated overnight to cool the exhaust gases.

On the day of the run, the start-up burner is discontinued and gas is introduced through the gas manifold to further heat the combustor bed to 1800 to $2000 \mathrm{~F}$. The electrical heaters on the gasifier are turned on and preheated nitrogen and superheated steam are introduced to the gasifier. At this time sand circulation is initiated to heat the gasifier to the desired operating temperature by controlling nitrogen flow to the L-valve. After steady state operation is established at the desired temperatures, the RDF feed is introduced to the gasifier. Combustor temperature and L-valve flows are adjusted to maintain desired steady state operating conditions. The process gas is analyzed throughout the run and the various data recorded and 
stored to calculate gas production, carbon conversion and fuel utilization efficiency.

Typically, an experiment is completed in an 8 to $10 \mathrm{hr}$ shift after overnight heat-up. This allows for 3 to 5 hrs steady state of data collection.

\section{RESULTS AND DISCUSSION}

\section{$\underline{\text { Objectives }}$}

. The primary objective of the program was the demonstration of the feasibility of gasifying a commercial RDF in the existing Battelle PRU. Secondary objectives for the program were (1) to obtain process data from gasification of RDF, (2) to compare this data with the extensive wood gasification data base, and (3) to incorporate this data into an existing heat and material balance model to predict thermal performance of a commercial system using RDF as the feedstock.

All of these objectives were met during the program. A discussion of the results follows.

\section{$\underline{\text { RDF Selection }}$}

Commercial grade RDF was chosen as the preferred initial feedstock for the experimentation in the PRU. Two likely suppliers were identified, the City of Madison, Wisconsin and National Ecology in Baltimore, Maryland. RDF from National Ecology was used for the PRU tests run due to availability and shipping problems in acquiring material from Madison.

The Baltimore facility is a state-of-the-art process which produces a "fluff" material that is later sold as fuel. A large fraction of the fuel is burned in boilers at the local Baltimore Gas and Electric site. In the National Ecology plant, incoming waste undergoes primary shredding, followed by removal of ferrous material. The remaining material is air classified with the light fraction going to a screening operation to remove fine glass and grit. The screen over material undergoes secondary shredding which produces 
the final 1-inch RDF product. Seasonal variations in ash content of the material have been reported but these are relatively modest with total ash content varying from $6.5 \%$ to $13 \%$ with an average of $9.24 \%$. No significant variation in ash composition or fusion point has been reported. The level of preparation in the national Ecology plant then produces a relatively stable, reliable feedstock. Later phases of this development program will investigate whether this degree of RDF preparation is necessary or a more modest preparation technique could be used.

Shakedown Testing

Initial operations in the PRU identified necessary modifications to the PRU feeder so a stable, reproducible RDF feed rate could be obtained. The nature of the RDF fed was such that it tended to pack in the lock hoppers and bridge over the screws in the metering bin. Tom Miles (the designer of the original feed system) was consulted to provide design modifications to the feed system which alleviated the feed problems.

The modifications made to the feed system included, replacement of the metering screws with a different size; addition of a straight sided liner to the metering bin; addition of an inverted conical liner to the lock hopper; and modification of the intersection of the horizontal and vertical conveying augers. An overall view of the feed system was shown in Figure 9. These modifications provided a continuous feed rate of about $400 \mathrm{lb} / \mathrm{hr}$ to the gasifier. A feed rate of $600 \mathrm{lb} / \mathrm{hr}$ could be reached for short periods of time, but the cycle times required for the lockhopper valves restricted higher rates from being achieved.

A further limitation to high feed rates was related to the RDF itself. The "fluff" material while having a packed bulk density near that of wood $\left(\sim 8 \mathrm{bb} / \mathrm{ft}^{3}\right)$ became a material with a bulk density in the range of 1 $\mathrm{lb} / \mathrm{ft}^{3}$ after handling. For a $400 \mathrm{lb} / \mathrm{hr}$ feed rate $400 \mathrm{ft}^{3}$ of material must be handled. This corresponds to $34 \mathrm{fills}$ of the lock hopper per hour or one $\mathrm{fi} 11$ every 1-3/4 minutes. This rate is the maximum that can. be achieved with the existing feed system. As was the case with wood, the feed system was the 
FIGURE 9

\section{CONVERSION VS TEMPERATURE}

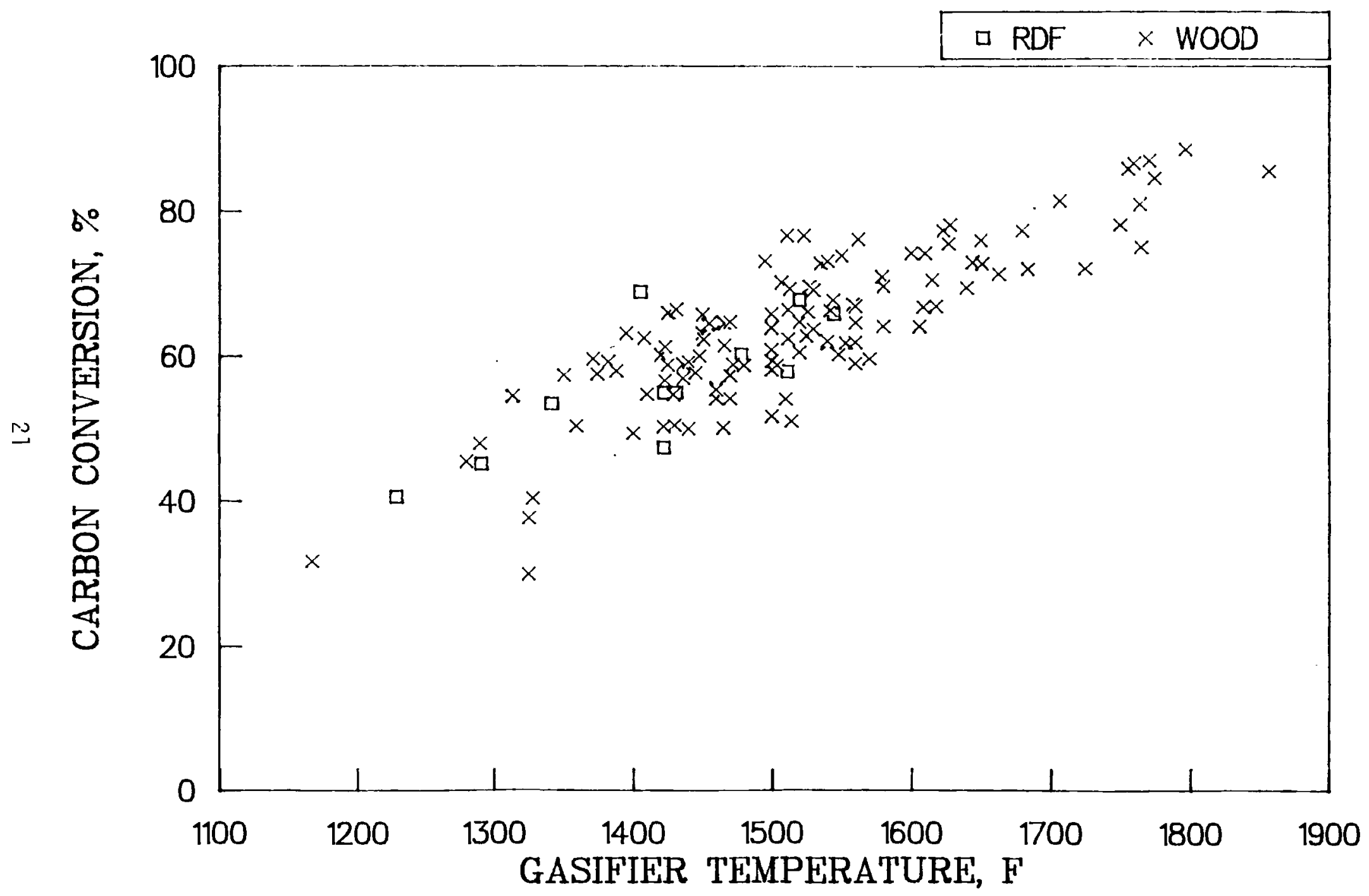


limiting factor in throughput achievable with the system. In commercial operation this type of limitation can be overcome by adding an additional feed system or a large lock hopper system.

\section{$\underline{\text { Testing and Data Acquisition }}$}

Within the 10 PRU runs made during the program, 11 test data periods were achieved that were of sufficient duration to provide data on the system performance. The overall results from these data periods are found in Table 3. The calculational procedure utilized was documented in the wood gasification final report ${ }^{(2)}$ and is included in Appendix B.

In addition to the primary variable of interest, gasifier performance, all other systems within the PRU were evaluated during these tests. The data in Table 3 were generated from steady state periods in which char produced during gasification was completely consumed within the combustor. As in the case of previous testing with wood, carbon (char) losses from the gasifier and combustor outlet gas streams were insignificant. The design of the PRU is such that natural gas is maintained to the combustor during operation to balance heat losses typical in pilot scale equipment.

Such operation allows a more accurate simulation of full scale operation to be made, and thus provides better process data to be generated. During most of the data periods, carbon balances around the PRU combustor showed that char conversion was complete, which again agrees with the extensive wood data base.

Gas analyses of the combustor flue gas stream showed that no CO or $\mathrm{SO}_{2}$ was formed in spite of the low excess air levels normally used during PRU operation ( $0.1 \%$ to $0.5 \%$ excess oxygen). Combustor performance was investigated in detail during the wood gasification program and is reported in reference 2 .

\section{Gasifier Temperature}

Gasifier temperature, as in the case of wood gasification, was the dominant gasifier variable. Carbon conversion levels measured did not vary 
TABLE 3. RDF GASIFICATION RUN RESULTS - 10 INCH GASIFIER

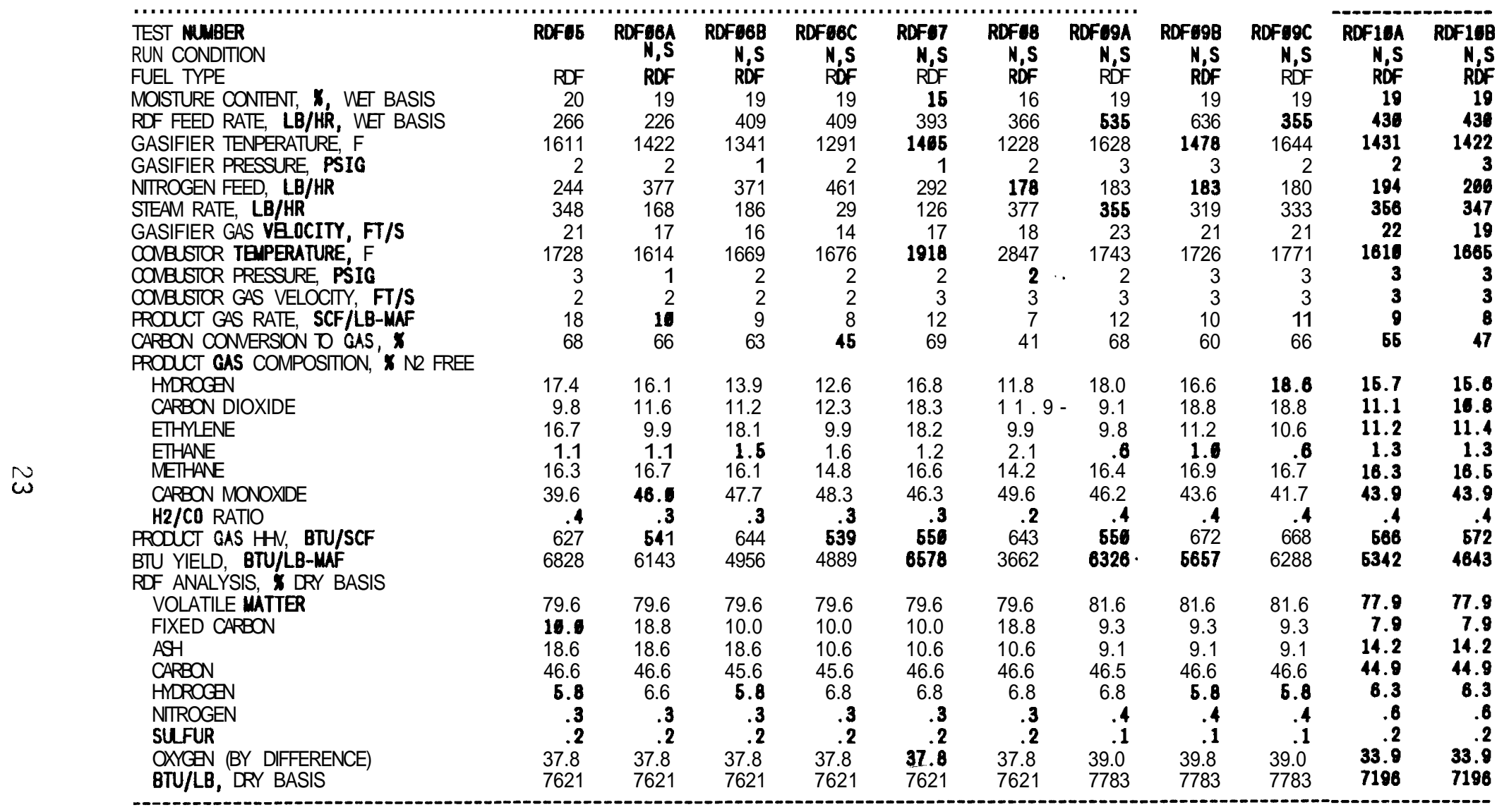

N - NITROGEN

$S$ - STEAM 
significantly with other measured variables such as RDF composition, ash content, or moisture content.

Carbon conversion figures for the RDF tests were essentially the same as those measured during the wood gasification experiments. This is illustrated in Figures 9 and 10. Figure 9 shows all of the wood gasification data ( $x$ 's) along with the RDF data (squares). As is seen, no difference in carbon conversion can be detected between the two fuels. This is an expected result because of the chemical similarity of the two materials as discussed below. The non-homogeneous character is reflected in Table 4. Ash content of the RDF varied along with the concentration of other components. Three detailed sample analyses were made of the RDF feed material during the program. One early in the testing, one at the mid point of testing, and one near the end. Data on ash fusion was obtained for each of the samples. These results, shown in Table 5, show that the National Ecology RDF preparation effectively removes low melting ash constituents from the NBN. These ash fusion temperatures (particularly the initial deformation temperature) were useful in determining combustor operating temperatures. If combustor temperatures near the ash fusion temperature were reached, small agglomerates were formed in the combustor bed during the tests. If lower temperatures were used, such agglomerates did not form. Since "balanced" operation is achieved at a gasifier temperature of 1550 , severe operating problems should not be encountered using a prepared RDF. Balanced operation of the process provides the capability to completely consume the feed material without producing unwanted solid byproducts. The gas production rates are thus maximized.

\section{Product Gas Heating Value}

The medium Btu product gas generated from the RDF had a heating value of 550 to $600 \mathrm{Btu} / \mathrm{scf}$. This level is higher than the heating value expected with wood as the feedstock.

The heating value of the product gas is consistent regardless of the operating conditions in the gasifier or variability of the RDF feed itself.

This result again duplicates test data generated with wood. The heating value consistency is illustrated in Figure 11, which shows its consistency with 
FIGURE 10

\section{CONVERSION VS TEMPERATURE}

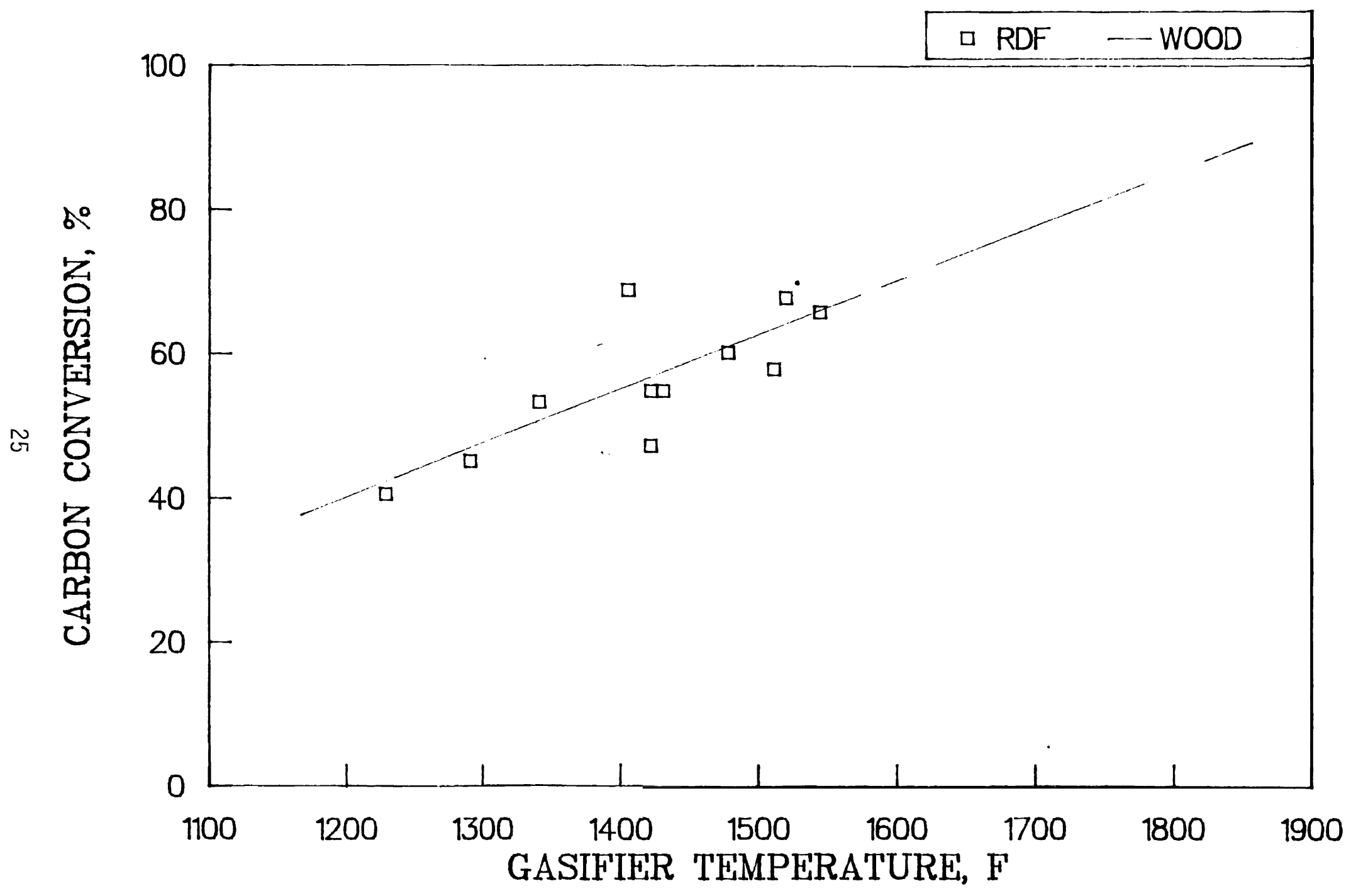


TABLE 4. RDF CHEMICAL ANALYSES

\begin{tabular}{lccc}
\hline & \multicolumn{3}{c}{$\%$ Dry Basis } \\
\cline { 2 - 4 } & $4 / 24 / 89$ & $5 / 5 / 89$ & $5 / 11 / 89$ \\
\hline Volatile Matter & 79.56 & 81.59 & 77.92 \\
Fixed Carbon & 9.98 & 9.28 & 7.92 \\
Ash & 10.46 & 9.13 & 14.16 \\
$\mathrm{C}$ & 45.52 & 47.47 & 44.87 \\
$\mathrm{H}$ & 5.75 & 5.84 & 6.29 \\
$\mathrm{~N}$ & 0.29 & 0.38 & 0.55 \\
$\mathrm{~S}$ & 37.79 & 39.04 & 33.94 \\
$\mathrm{~S}$ & 0.19 & 0.14 & 0.19 \\
Btu & 0 & 0 & 0 \\
Moisture (As Received) & 7621 & 7783 & 7196 \\
& 19.38 & 22.49 & 19.47 \\
\hline \hline
\end{tabular}

TABLE 5. RDF ASH ANALYTICAL RESULTS

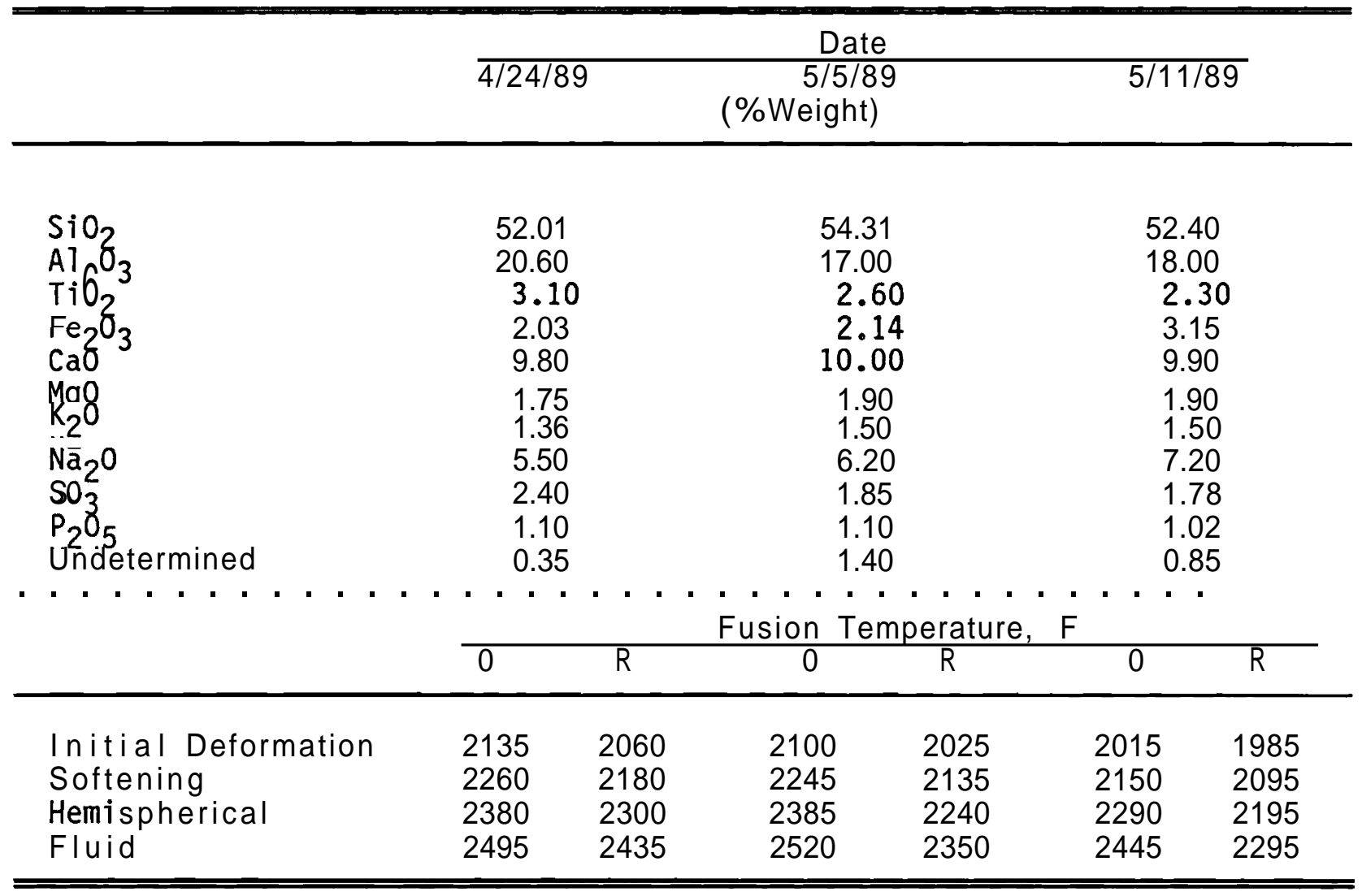


FIGURE 11

\section{HEATING VALUE VS FEED RATE}

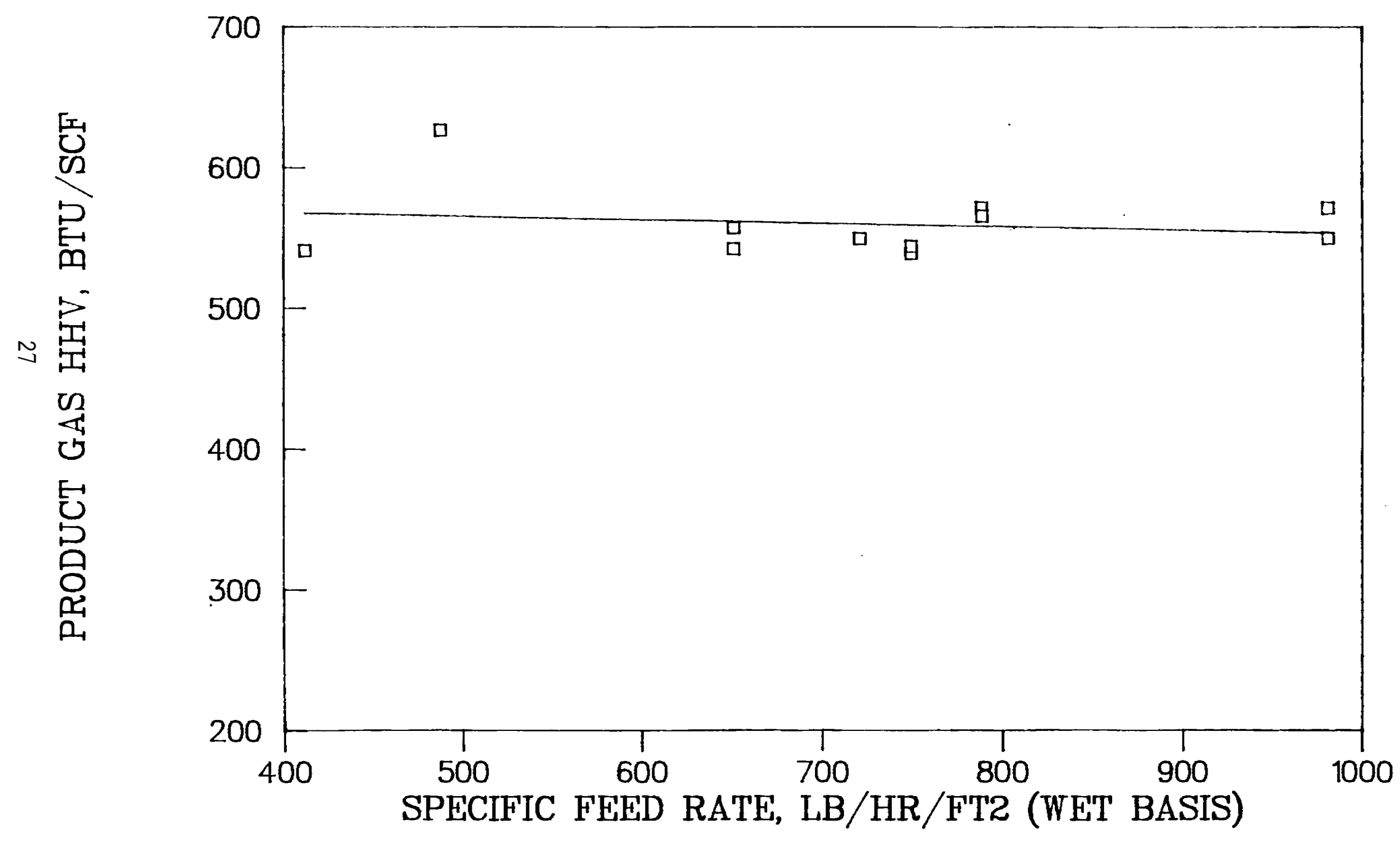


reactor throughput. The consistency of the heating value provides the ability to use conventional (volumetric) control systems on combustion equipment utilizing the gas. Control of the total plant then is simplified since the only adjustment necessary is RDF feed rate -- a simple control. A typical analysis of the RDF derived product gas is found in Table 6 . The heating value of this gas is such that combustion equipment designed for natural gas can utilize the gas without burner modifications.

\section{Waste Water}

As part of the required Ohio EPA permitting process, waste water samples were taken at the outlet of the Battelle treatment system. This treatment is very simple consisting of a settling chamber, a sand filter, and a charcoal filter. This simple treatment system was adequate to provide a water discharge that is within EPA drinking water standards. These results are tabulated in Appendix A.

These results, although preliminary, show the potential ease of waste water cleanup from the Battelle gasifier. Condensibles were analyzed in detail during the wood gasification development. These analyses showed that the condensibles produced were relatively insoluble in water thus greatly simplifying projected waste water cleanup requirements.

TABLE 6. TYPICAL RDF DERIVED PRODUCT GAS ANALYSIS

\begin{tabular}{cc}
\hline Component & $\%$ Vol ume \\
\hline $\mathrm{H}_{2}$ & 15.7 \\
$\mathrm{CO}_{2}$ & 11.1 \\
$\mathrm{C}_{2} \mathrm{H}_{2}$ & 11.2 \\
$\mathrm{C}_{2} \mathrm{H}_{6}$ & 1.3 \\
$\mathrm{CH}_{4}$ & 16.3 \\
$\mathrm{CO}$ & 43.9 \\
$\mathrm{HHV}$, Btu/SCF & 566 \\
\hline
\end{tabular}


$\underline{\text { Tar Production }}$

Within the limited testing program conducted, lower concentrations of condensed organic materials were generated than with wood. A much more extensive evaluation of the tar production will be necessary to quantify this result. Longer PRU tests must be conducted to provide sufficient quantities of tar for analysis, and to accurately calculate a production rate. During the RDF tests run during this brief program, no collectable tar materials were found suggesting more favorable production levels than those measured with wood. The mode of operation with RDF is identical to that with wood so the character of any condensed materials is expected to be similar to that found with wood.

\section{Gasifier Throughput}

Although the high throughputs obtained during the wood gasification program could not be reached, the data obtained during operation with RDF showed that no effect on carbon conversion, gas heating value, or performance was noticed with changes in reactor throughput. The highest throughput achieved during these tests was about $1000 \mathrm{lb} / \mathrm{hr}-\mathrm{ft}^{2}$. This throughput is significantly lower than the $4500 \mathrm{lb} / \mathrm{hr}-\mathrm{ft}^{2}$ achieved with wood but is high enough to demonstrate the feasibility of gasifying large quantities of RDF in a compact reactor system. Performance of the system showed that the limitation was the capacity of the feed system. Much higher reactor throughputs can be achieved if the existing feed system was modified.

\section{PROJECTED PROCESS ECONOMICS}

The similarity in performance of RDF in the Battelle Gasification Process to that with wood provides a basis for a preliminary estimation of the economics of RDF gasification. RDF plants will generally be located at sites that are somewhat remote from gas users and so the preferred product from a gasification plant will be electric power rather than medium Btu gas. The 
production of medium Btu gas provides a means to maximize power production from an RDF plant since the efficiency of gas turbine generation is higher than steam turbine based power production.

Data generated during this test program was incorporated into a process heat and material bal ance model to predict commercial scale production rates with $\mathrm{RDF}$ as the feedstock. A copy of the computer printout for a 1000 TPD plant is found in Figure 12.

A 2000 TPD RDF gasification plant will produce $898 \mathrm{mill}$ ion Btu/hr of a medium Btu product gas. This quantity of gas will generate about $112 \mathrm{MW}$ of power. A similar quantity of MSW in a mass burn plant will generate only 60 MN of power.

Capital costs are also quite different for the two systems. Using capital costs generated for a commercial scale, 200 TPD wood gasification system scaled up to the 2000 TPD plant size predicts an overall commercial scale capital cost of $\$ 89$ million. A major element in this cost is the gas turbines themselves which are estimated to be $\$ 44.8$ mil lion using cost figures provided by turbine vendors. The overall cost comparison is shown in Table 7. The mass burn figures in the table are from literature references for the Baltimore, Maryland mass burn facility being operated by Wheelabrator. The production of medium Btu gas from RDF provides the ability to produce larger quantities of power from RDF while also providing a user of the technology with the potential to use the gas in other industrial combustion processes.

\section{TABLE 7. ECONOMIC COMPARISON RDF GASIFICATION VERSUS MASS BURN}

\begin{tabular}{lcc}
\hline & Mass Burn & Gasification \\
\hline Plant Size, TPD & 2000 & 2000 \\
Capital Costs (\$X106) & & \\
RDF Preparation & & $25(\mathrm{a})$ \\
Conversion (Gasifier or Combustor) & $\star \star$ & 19.2 \\
Turbines & $170^{(3)}$ & 89.8 \\
Total Capital Cost & $60^{(3)}$ & 112 \\
Power Capacity, MW & & \\
\hline
\end{tabular}


$\underset{X X X X}{X}$ MASS AND ENERGY BALANCE SUMMARY FOR FOREST RESIDUE GASIFICATION MODEL XXXX
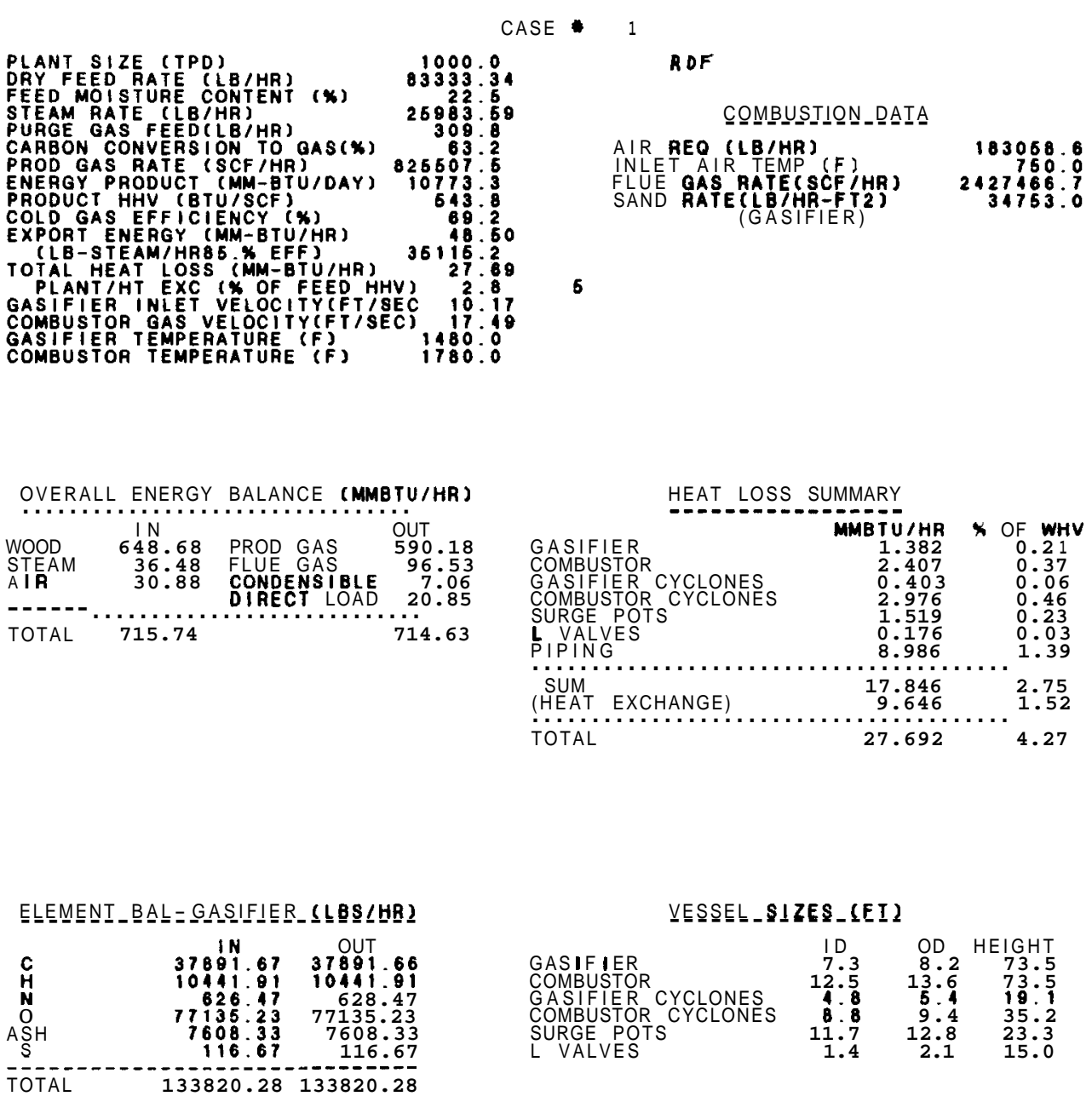

DETAILED MASS AND ENERGY BALANCE
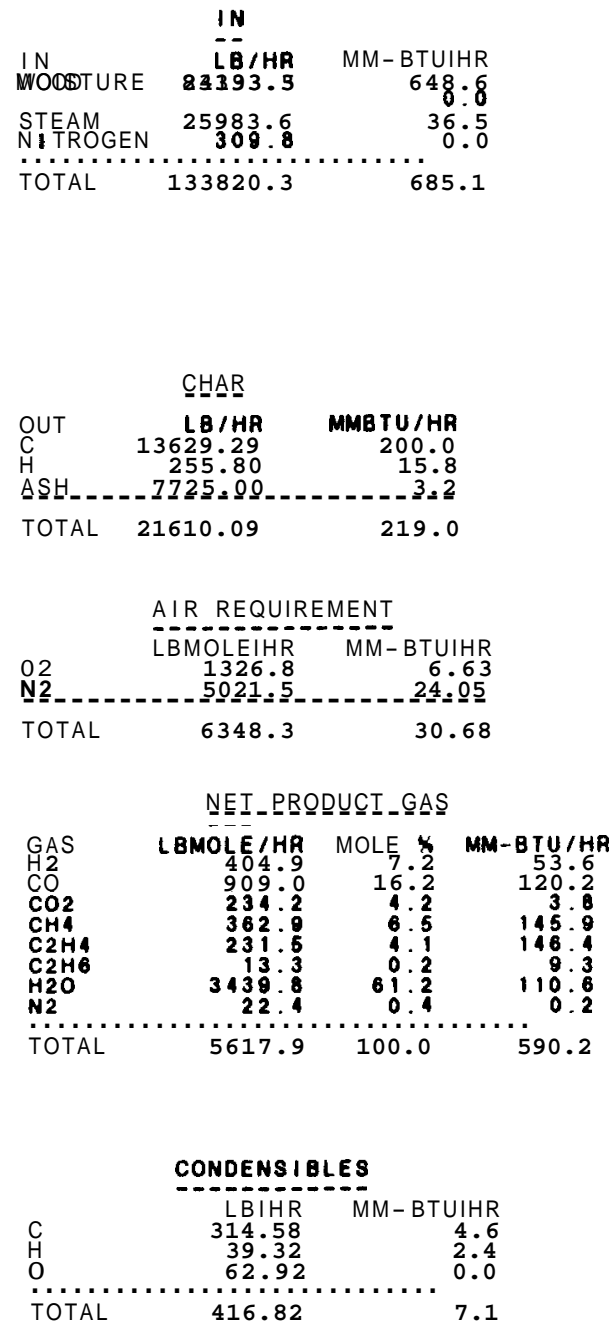

ELUE_GAS

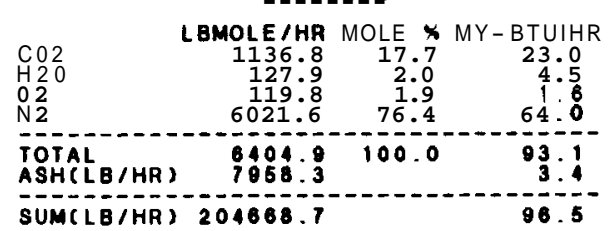


This analysis, while preliminary, demonstrates the economic potential for the gasification of RDF to produce medium Btu gas.

\section{CONCLUSIONS AND RECOMMENDATIONS}

The Battelle High Throughput Gasification Process has been shown to be an effective means to produce a high energy density medium Btu gas from a variety of biomass feedstocks. The extensive data base generated for wood has demonstrated the competitive economics compared to conventional technologies. The successful use of wood in the process led to the current investigation of a means of producing a medium Btu gas from RDF. The use of RDF in the process has been evaluated and shown to produce a gas having a heating value of over $550 \mathrm{Btu} / \mathrm{scf}$ without encountering ash agglomeration problems that might be expected with RDF.

The economics of the process, although preliminary, show that the technology can compete favorably with mass burn technology in the market place. The specific return from a commercial plant utilizing RDF is highly site specific and depends to a large extent on tipping fees. The capital costs, on the other hand are projected to be about half of a similarly sized mass burn facility.

Further development of the RDF gasification process is necessary before the technology can be commercially implemented. Detailed design data must be generated so that an architect/engineering firm can have the data necessary to construct such a commercial scale facility. The technology must be at a sufficient scale of development so that municipalities with waste disposal problems can include gasification as a commercially available option for consideration. The development efforts then must continue at a rapid pace to provide the basis for commercial application of the technology.

Decisions by potential users of MSW technologies must be based on available technology and will of necessity prevent developing technologies from being utilized. Developing technologies then will have to wait until the life of the existing plants is over, usually 20 years. The Battelle 
technology can provide an alternative to current technologies, but only if ready for commercialization before decisions must be made by potential users of the technology.

Further testing is necessary to realize these benefits. Other variables that must be investigated include:

- Determination of the necessary level of RDF preparation.

- Modification of the feed system to provide higher reactor throughputs.

- Alternate sources of RDF.

- Installation of a small gas turbine to evaluate deposits that might form during power generation.

Completion of such a program will provide data for the successful commercial application of the technology.

\section{REFERENCES}

1. "Thermal Systems for Conversion of Municipal Sol id Waste", Vol. 4, Argonne National Laboratory, DE84-010490, March 1983.

2. Feldmann, H. F. et al., "Conversion of Forest Residues to a Methane Rich Gas in a High Throughput Gasifier", May 1988.

3. Waste Age, Vol. 18, No. 11, p. 203. 

APPENDIX A

WASTE WATER EFFLUENT ANALYSES 



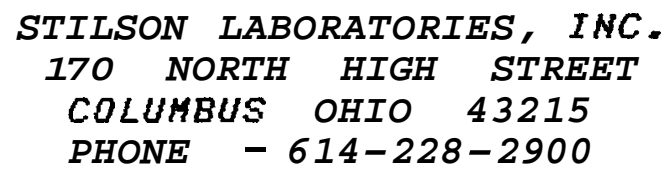

BATTELLE MEMORIAL INSTITUTE

505 KING AVE.

COLUMBUS, OHIO 43201

$L A B$ NO, 9435

JOB 958245

DATE June 5, 1989

ATTN: HR. PAT GORMAN

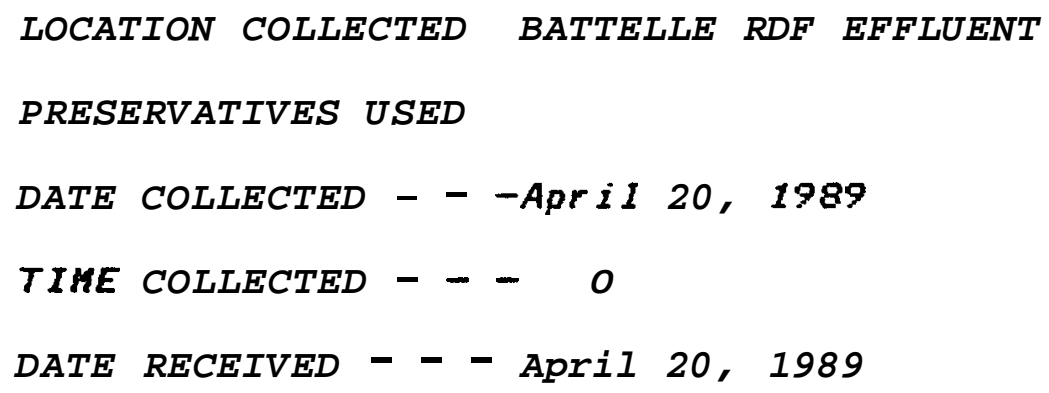

Test

COLOR

PH, LAB

RES TOT NONEILT

$T K N$ (N)

AMKONIA (N)

NITRITE (N)

NITRATE (N)

PHOS: TOTAL (P)

SULFIDE

SULFITE

SULFATE

FLUORIDE

CYANIDE, TOTAL

HAGNESIUH

ALUHINUH
Result

Unit

15

$c u$

7.60

$S U$

6

$M G / L$

2.15

$H G / L$

0.18

$H G / L$

0.12

$H G / L$

0.47

$M G / L$

10.02

$H G / L$

$<0.02$

$M G / L$

2

$H G / L$

50

$H G / L$

0.78

HO/L

0.011

$H G / L$

5.2

$H G / L$

$<200$

$U G / L$ 


\begin{tabular}{|c|c|c|}
\hline ANTIMONY & $<200$ & $U G / L$ \\
\hline ARSENIC & $<5.0$ & $U G / L$ \\
\hline BARIUH & $<200$ & $U G / L$ \\
\hline$B E R Y L L I U M$ & $<20$ & $U G / L$ \\
\hline BORON & $<5.0$ & $H G / L$ \\
\hline CADHIUH & $<10$ & $U G / L$ \\
\hline CHROMIUH, TOTAL & $<30$ & $U G / L$ \\
\hline COBALT & $<20$ & $U G / L$ \\
\hline COPPER & $<15$ & $U G / L$ \\
\hline IRON, TOTAL & 160 & $U G / L$ \\
\hline$\angle E A D$ & $<30$ & $U G / L$ \\
\hline HANGANESE & $<20$ & $U G / L$ \\
\hline MERCURY & $<0.2$ & $U G / L$ \\
\hline MOLYBDENUH & $<100$ & $U G / L$ \\
\hline NICKEL & $<30$ & $U G / L$ \\
\hline SELENIUM & $<5.0$ & $U G / L$ \\
\hline$S I L V E R$ & $<20$ & $U G / L$ \\
\hline THALLIUH & $<100$ & $U G / L$ \\
\hline TIN & $<500$ & $U G / L$ \\
\hline TITANIUM & $<200$ & $U G / L$ \\
\hline$Z I N C$ & $<20$ & $U G / L$ \\
\hline TOTAL ORGANIC CARBON & 2 & $H G / L$ \\
\hline HBAS & $<0.02$ & $H G / L$ \\
\hline OIL AND GREASE & 3 & $H G / L$ \\
\hline PHENOL & 89 & $U G / L$ \\
\hline$B O D$ & 2 & $H G / L$ \\
\hline$C O D$ & 37 & $H G / L$ \\
\hline RESIDUAL CHLORINE & $<0.1$ & $H G / L$ \\
\hline
\end{tabular}

A. 2 


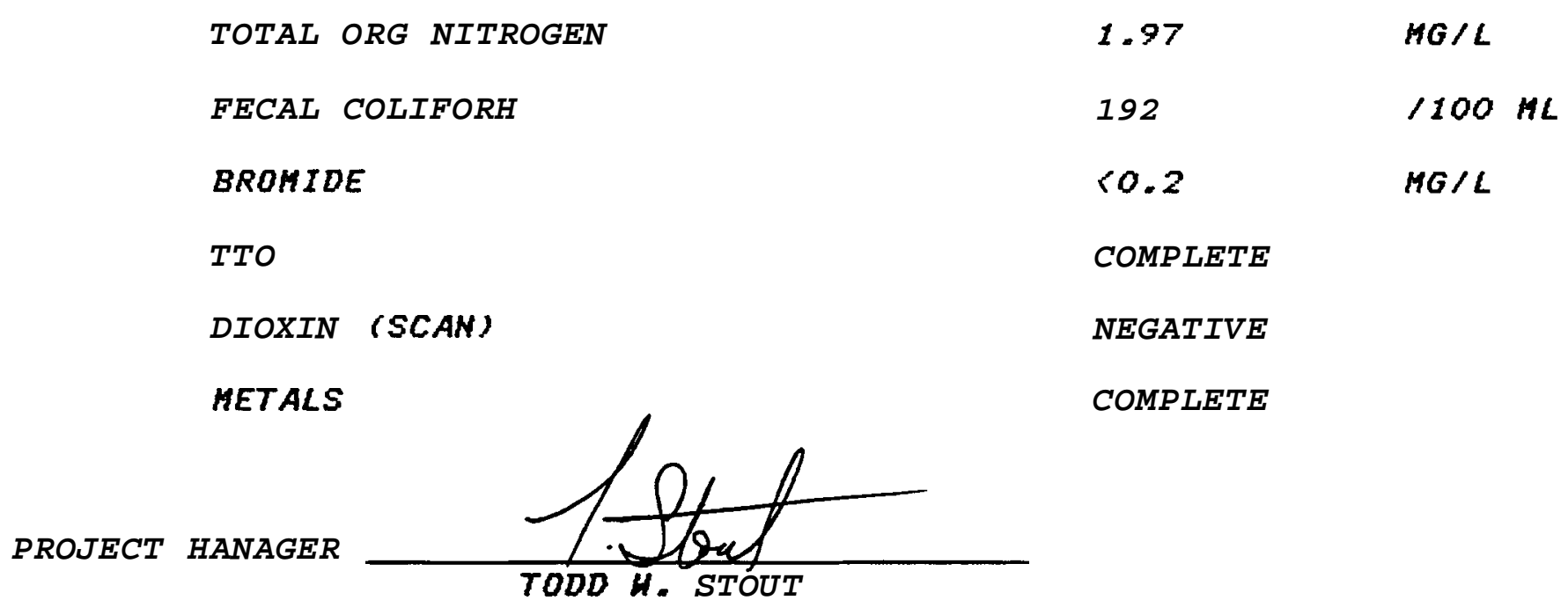




\section{BATELLE MEMORIAL INSTITUTE \\ UOLATILES EPA 624 \\ RDF EFFLUENT}

SLI $\# 9435$

COMPOUND

CONC $M G / L$

BENZENE

$B$ is (CHLOROMETHYL) ETHER

$<0.01$

$<0.01$

BROWOOICHLOROMETHANE

$<0.01$

BROMOFORH

BROMOHETHANE

CARBON TETRACHLORIDE

CHLOROBENZENE

CHLOROETHANE

2-CHLOROETHYLVINYL ETHER

CHLOROFORM

CHLOROMETHANE

DIBROHOCHLOROMETHANE

DICHLORODIFLUOROMETHANE

1,1-DICHLOROETHANE

$1,2-D$ I CHLOROETHANE

1,1 -D I CHLOROETHENE

trans-1,2-DICHLOROETHENE

$<0.01$

$<0.05$

$<0.01$

$<0.01$

$<0.05$

$<0.03$

$<0.01$

$<0.05$

$<0.01$

$<0.01$

$<0.01$

$<0.01$

$<0.01$

1,2 -D ICHLOROPROPANE

1,3-D I CHLOROPROPENE

ETHYL BENZENE

METHYLENE CHLORIDE

$1,1,2,2$-TETRACHLOROETHANE

$<0.01$

$<0.01$

$<0.01$

$<0.01$

$<0.01$

TETRACHLOROETHENE

TOLUENE

$1,1,1$-TR I CHLOROETHANE

$1,1,2$-TR I CHLOROETHANE TRICHLOROETHENE

$<0.01$

$<0.01$

$<0.01$

$<0.01$

$<0.01$

$<0.01$

TRICHLOROFLUOROMETHANE

$<0.01$

VINYI CHLORIDE

1, 4-DICHLOROBENZENE

1,3-DICHLOROBENZENE

1,2-D I CHLOROBENZENE

$<0.05$

$<0.01$

$<0.01$

$<0.01$

XYLENE

$<0.01$ 
BATELLE MEMORIAL INSTITUTE

BASE NEUTRALS EPA 625

RDF EFFLUENT

SLI\# 9435

$\underline{\text { COMPOUND }}$

CONC MG/L

1,3-DICHLOROBENZENE

$<0.01$

$1,4-D I C H L O R O B E N Z E N E$

$<0.01$

HEXACHLOROETHANE

$<0.01$

$B$ is (2-ch loroethyl) ETHER

$<0.02$

1,2-DICHLOROBENZENE

$<0.01$

$B$ is (2-ch loro i sopropyl)ETHER

$<0.02$

n-NITROSODI-n-PROPYLAMINE

$<0.03$

NITROBENZENE

HEXACHLOROBUTADIENE

$1,2,4-T R I C H L O R O B E N Z E N E$

ISOPHORONE

NAPHTHALENE

$<0.01$

$<0.01$

$<0.01$

$<0.01$

$<0.01$

BIS-(2-ch loroethoxy) METHANE

$<0.02$

HEXACHLOROCYCLOPENTADIENE

$<0.01$

2-CHLORONAPHTHALENE

ACENAPHTHYLENE

$<0.01$

$<0.01$

ACENAPHTHENE

DIHETHYL PHTHALATE

$<0.01$

$<0.01$

2,6-DINI TROTOLUENE

FLUORENE

4-CHLOROPHENYL PHENYL ETHER

$<0.02$

$<0.01$

2 , 4-DINITROTOLUENE

DIETHYLPHTHALATE

N-NITROSODIPHENYLAMINE

HEXACHLOROBENZENE

$<0.02$

$<0.02$

$<0.01$

$<0.03$

$<0.01$

$<0.02$

4-BROMOPHENYL PHENYL ETHER

$<0.01$

PHENANTHRENE

$<0.01$

ANTHRACENE

DI-n-BUTYL PHTHALATE

FLUORANTHENE

PYRENE

BENZIDENE

BUTYL BENZYL PHTHALATE

Bis (2-ethylhexyl)PHTHALATE

CHRYSENE

BENZO(a) ANTHRACENE

3,3 '-DICHLOROBENZI DENE

Di-n-OCTYLPHTHALATE

BENZO(b) FLUORANTHENE

BENZO(k)FLLURANTHENE

BENZO( a)PYRENE

INDENO $(1,2,3-c, d)$ PYRENE

$<0.01$

$<0.01$

$<0.01$

$<0.01$

$<0.01$

$<0.01$

$<0.01$

$<0.01$

$<0.02$

$<0.01$

$<0.01$

$<0.01$

$<0.01$

$<0.01$

DIBENZO $(a, h)$ ANTHRACENE

$<0.01$

BENZQ (gh i ) PERYLENE

$<0.01$

N-NITROSODIMETHYL AMINE

$<0.03$ 


\section{BATELLE MEMORIAL INSTITUTE ACIDS EPA 625 \\ RDF EFFLUENT \\ SLI\# 9435}

\section{COMPOUND}

2-CHLOROPHENOL 2-NITROPHENOL PHENOL

2 , 4-DIMETHYLPHENOL

$2,4-D I C H L O R O P H E N O L$

$2,4,6-T R$ I CHLOROPHENOL

4-CHLORO-3-METHYLPHENOL

2 , 4-DINI TROPHENDL

2-METHYL-4,6-DINI TROPHENOL

4-NITROPHENOL

2-METHYL PHENOL

3-METHYL PHENOL

4-METHYL PHENOL
CONC $M G / L$

$<0.01$

$<0.01$

$<0.01$

$<0.01$

$<0.01$

$<0.01$

$<0.01$

$<0.01$

$<0.01$

$<0.01$

$<0.01$

$<0.01$

$<0.01$ 


\section{BATELLE MEMORIAL INSTITUTE \\ PESTICIDES/PCBS EPA 625 \\ RDF EFFLUENT}

SLI\# 9435

COMPOUNO

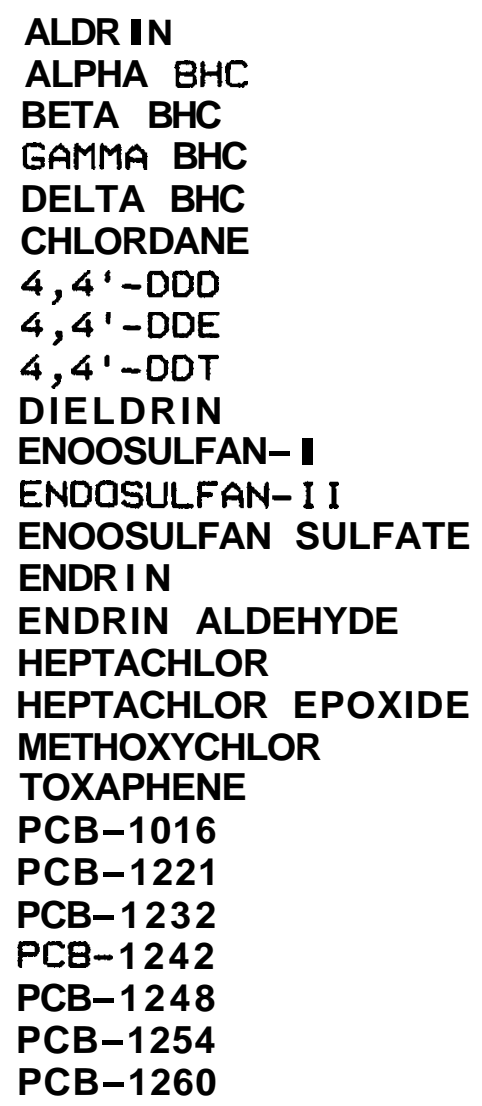

CONC MG/L

$<0.01$

$<0.01$

$<0.01$

$<0.01$

$<0.01$

$<0.01$

$<0.01$

$<0.01$

$<0.01$

$<0.01$

$<0.01$

$<0.01$

$<0.01$

$<0.01$

$<0.01$

$<0.01$

$<0.01$

$<0.01$

$<0.01$

$<0.01$

$<0.01$

$<0.01$

$<0.01$

$<0.01$

$<0.01$

$<0.01$ 

APPENDIX B

SAMPLE CALCULATIONS AND STATISTICAL ANALYSIS 



\section{APPENDIX}

\section{SAMPLE CALCULATIONS AND STATISTICAL ANALYSIS}

\section{PRU Calculations}

Calculation of the major flows and carbon conversion are accomplished as follows:

The major flows of steam, nitrogen, air, and natural gas are all based on pressure drop across an orifice. This gives an equation of the type

$$
\text { Flow }=K \sqrt{\mathrm{p \Delta P}}
$$

where $\mathrm{K}$ is a constant calculated from the orifice and pipe sizes, is density calculated from the material and its temperature and pressure. $P$ is the pressure drop across the orifice.

Product gas flow is calculated from the nitrogen flow and product gas composition using a ratio of nitrogen content of the product gas to nitrogen flow into the gasifier.

\section{Product Gas Flow $=$ Nitrogen Flow/Fraction Nitrogen in Product Gas}

The most important calculation is carbon conversion.

$$
\text { Carbon Conversion }=\left(\frac{\text { Moles } \mathrm{N}_{2} \text { Into Gasifier }}{\mathrm{N}_{2} \text { Content in Product }} \times \frac{\text { Carbon Content in Product } \cdot 12}{\text { Wood Foed Rate } \times \text { Yood Carbon Content }}\right)
$$

Carbon conversion is calculated by taking the amount of carbon in the product gas divided by the feed carbon. The values are calculated from the product gas composition, flows of nitrogen and wood feed, and feed analysis for carbon. Much effort is given to the accuracy of this calculation since carbon conversion is directly related to gas production and efficiency. This concern led us to conduct a statistical analysis of the data. 


\section{Statistical Analysis of Experimental Data}

Examination of all the data generated during this program indicates that carbon conversion is primarily a function of gasifier temperature. However, there is a considerable amount of scatter in this data as shown in Figure B-1. Therefore, the following questions were posed.

(1) Is the scatter observed statistically consistent with the methods of measurement, analytical techniques, and calculational methods employed?

(2) What is the best fit to the data and what probability is there that the actual (as opposed to the calculated) carbon conversion will fall within certain values?

(3) How can the methods of raw data measurement and analytical techniques be improved to reduce the scatter in calculated carbon conversion?

(4) Are there other parameters involved that perhaps have a second order effect on carbon conversion?

The first step in the statistical analysis was to eliminate data that, for known reasons, was faulty. Then, carbon conversion, the prime measure of performance, was plotted versus temperature, the main independent variable. Figure B-1 shows the linear regression and that the actual data are linear with gasifier temperature. A standard deviation of 5.8 percent is calculated for carbon conversion with respect to the regression. This is seen graphically by the band bounded by parallel lines in Figure B-1. This shows that another single observation (experimental test run) has a 68 percent probability of falling within this band. A precision analysis was conducted, calculating the variance in carbon conversion as a function of the variance in the operating parameters. This analysis indicates that the scatter observed is easily due to normal experimental errors.

What might be of more critical importance to the design and scaleup efforts is the accuracy of the regression line. That is, if the test set 


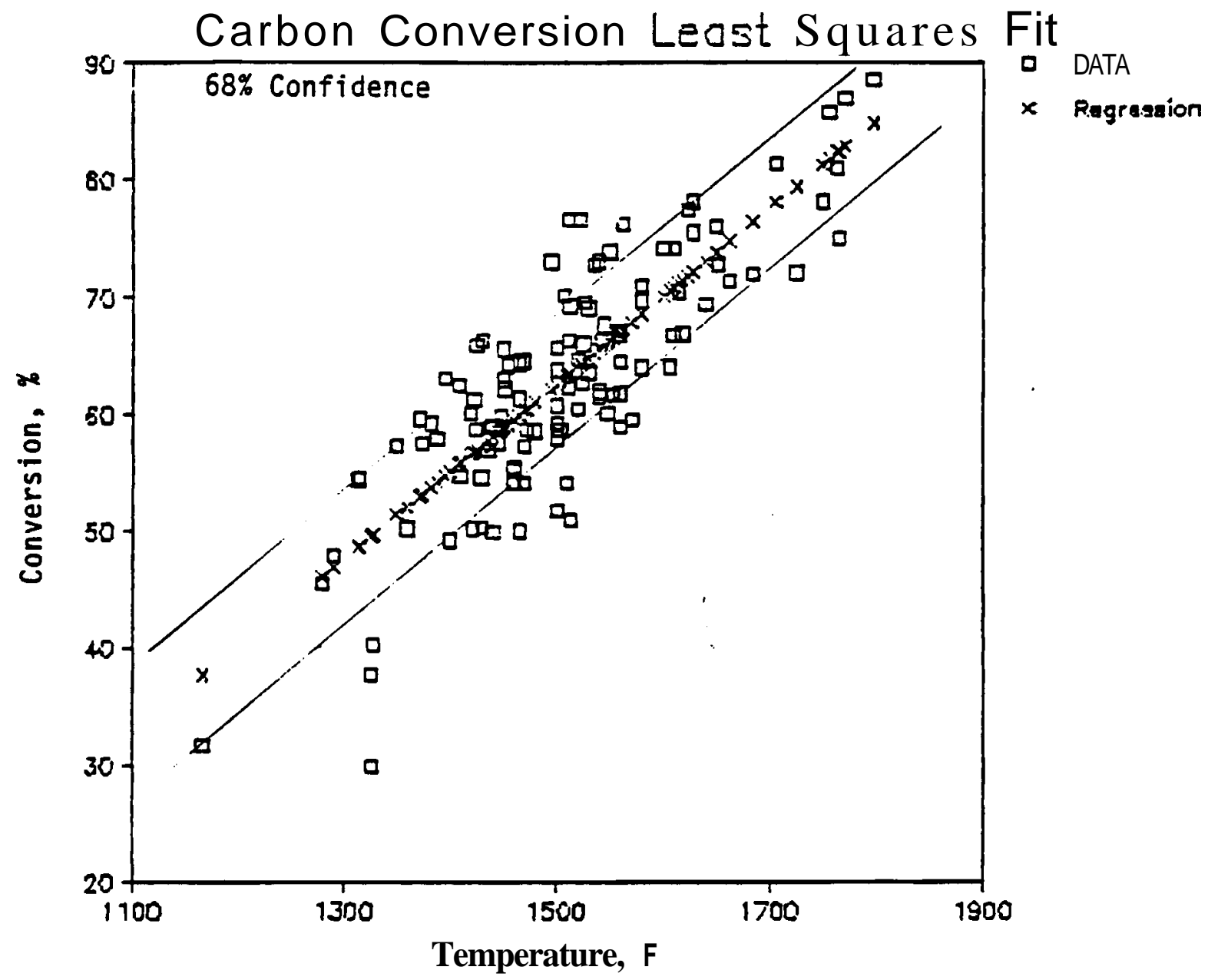

FIGURE B-1

(INCLUDES BOTH 6 AND 10 IN. GASIFIER DATA) 
were to be replicated, where would the new regression line be? This would indicate how close the given experimentally determined line is to the theoretical one. Figure B-2 presents the regression line with 95 percent confidence limits (i.e., there is a 95 percent probability that the theoretical line or replicate will fall within these bounds). As seen there is excellent agreement, especially in the range where operation is expected. This is almost an expected result in a statistical analysis, that means or averages behave much better with less scatter than single observations, almost by a factor of three in the present case.

It should be noted that performance, whether it be a pilot scale or commercial plant, will follow a curve not a single observation. Nothing can be said of the variance of a single observation in a commercial plant since the measurement techniques may vary from what is presently used. However, the average or theoretical curve should be the same. The only assumption implicit here is that the variances seen are random, which has been verified to some extent.

\section{Contributions to Error}

In order to understand and possibly decrease the experimental errors occurring, the relative contribution of individual measurement error to the overall variance in carbon conversion was studied. The total deviation in a dependent variable is the square root of the sum of the relative variance in each independent variable used to calculate it. This analysis also serves as a check on the calculation procedure. Since carbon conversion is the prime measurement of performance it was studied to determine contributions to the variance in the calculated carbon conversions. The measurements used in this calculation are: GC measurements of gas carbon and nitrogen content, nitrogen feed to the gasifier, feed rate of wood, and carbon content of the wood. Each of these component's contribution to the variance was determined. This is seen on a relative basis in Figure B-3. The error in the carbon conversion calculation is most sensitive to the measurements of the nitrogen in the product gas and nitrogen flow. It is somewhat less sensitive to carbon content of the product gas and the feed rate and relatively insensitive to measurement variances in the feed carbon content. 


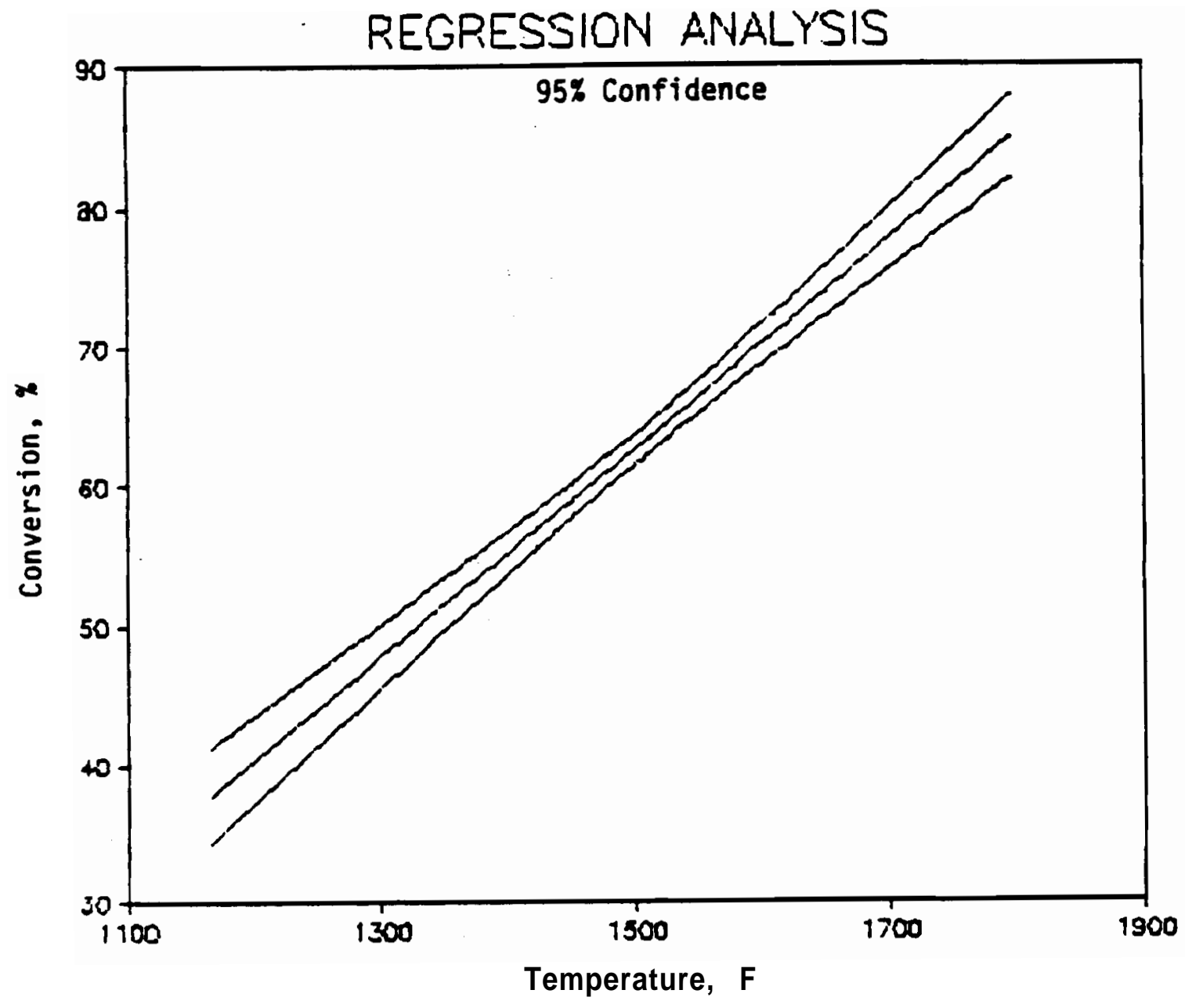

FIGURE B-2 


\section{SIGMA`2 CONTRIBUTION}

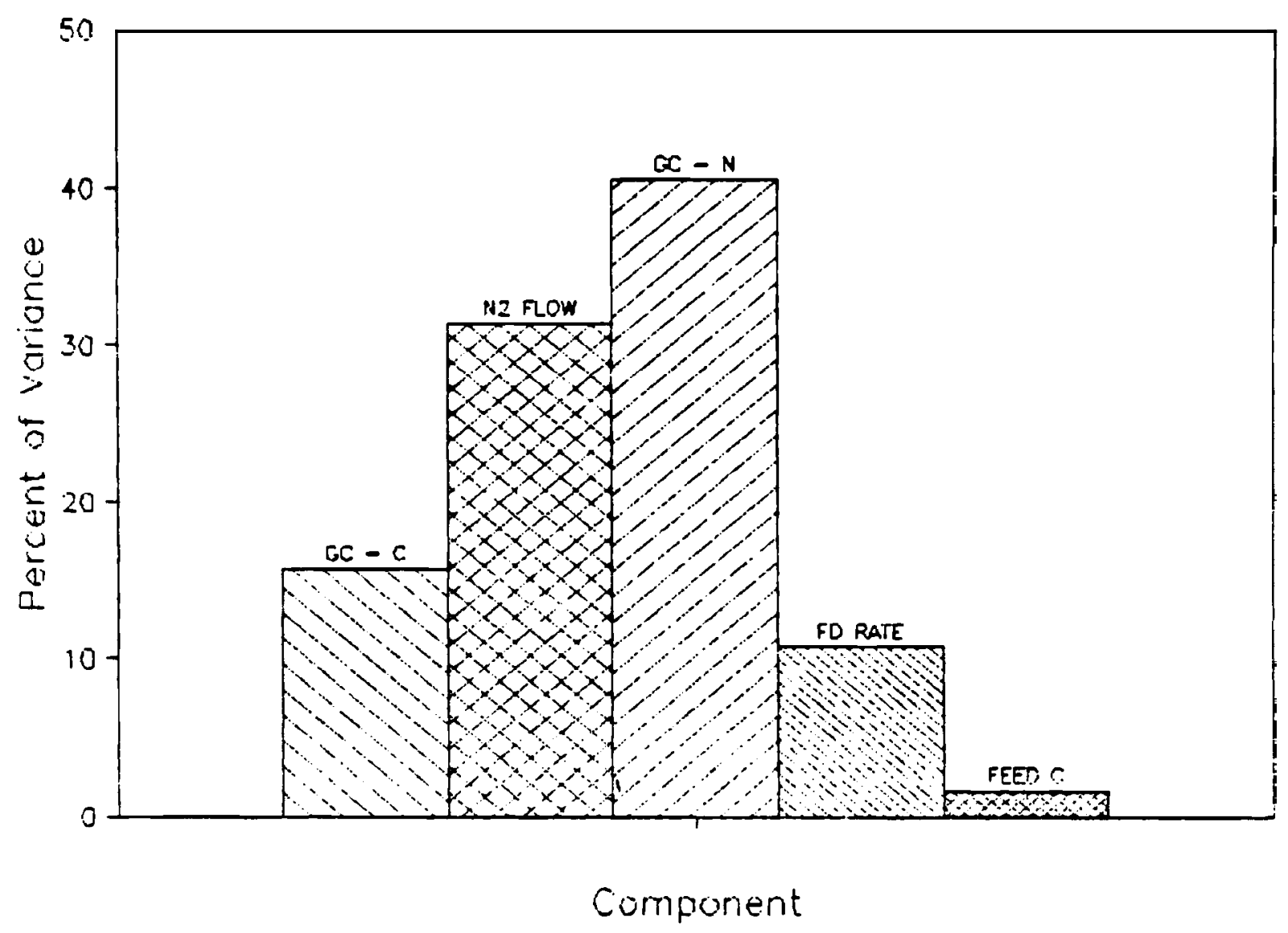

FIGURE B-3 


\section{Second Order Effects}

Although temperature appears to have the strongest effect of any independent variables, the data was analyzed for second order effects. To do this, a so called "statistical tree"(a) was constructed. Carbon conversion was again chosen as the performance predictor of importance. All independent variables were individually and equally divided into high and low values with a mean carbon conversion calculated in both ranges. Variables used included: temperature, feed rate, steam rate, feed moisture, gasifier pressure, inlet velocity, and air to the combustor, the last serving as a check for bias since air rate should have no direct effect on conversion. The variable,temperature, which resulted in the greatest difference (most effect on carbon conversion) between these means became the top level of the "tree". Then the process was repeated separately for only high temperature points then low temperature

points. The portrayal in Figure B-4 shows the dominant variable affecting carbon conversion at each level.

A surprising observation is the complete dominance of temperature in high temperature regions masking effects from the other variables studied. However, at low temperatures feed moisture has a significant effect on conversion. This may be due to the reduced rate of moisture vaporization at lower temperatures. Feed rate appears as a minor effect in that lower rates favor marginally higher conversions. At low temperature and high moisture condition's inlet velocity had a slightly greater effect than temperature. That high inlet velocities favored conversion may be due in part to the increased heat input supplied by the steam which helps vaporize the moisture at the lower temperatures. However, these effects are obscured somewhat since inlet velocities varied only over a narrow range at the lower temperatures.

The main conclusion here is that at the 65 to 75 percent control conversion levels of interest for commercial designs temperature has by far the dominant effect suggesting heat transfer in the gasifier will be the primary contributor to conversion, while lower wood feed rates marginally enhanced conversion.

(a) This approach was suggested by Dr. Ralph E. Thomas, retired Battelle staff member. 
CARBON CONVERSION

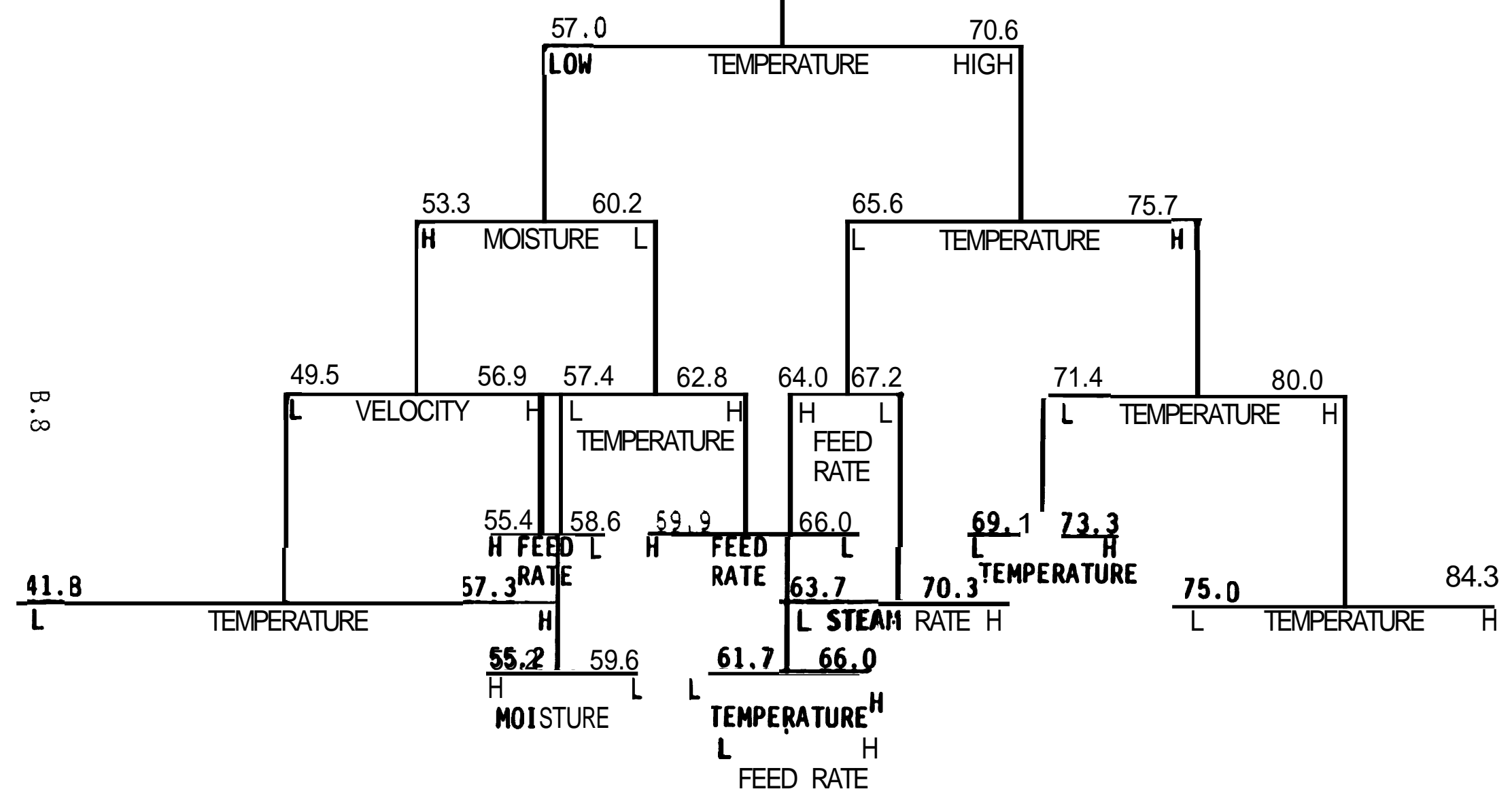

FIGURE B-4. STATISTICAL TREE ANALYSIS 
No. of

$\underline{\text { Copies }}$

OFFSITE

10 DOE/Office of Scientific and Technical Information

W. Ayres

Pyrotech, Inc.

8016 Stateline

Suite 101

Leawood, KS 66208

S. Babu

Institute of Gas Technology

IIT Center

3424 South State Street

Chicago, IL 60616

P. Badger

Southeastern Regional Biomass Energy Program

Tennessee Valley Authority

435 Chemical Building

Muscle Shoals, AL 35660

K. Birkinshaw

California Energy Commission

1516 - 9th Street, MS-43

Sacramento, CA 95814

R. Costello

Biofuels and Municipal Waste Technology Division

U.S. Department of Energy

Forrestal Building (CE-341)

1000 Independence Avenue

Washington, D.C. 20585

K. S. Creamer

Battelle-Columbus Division

505 King Avenue

Columbus, $\mathrm{OH} 43201$
No. of

Copies

K. Durai-Swamy

Manufacturing and Technology

Conversion International

Incorporated

13080 Park Street

Santa Fe Springs, CA 90670

H. F. Feldmann

Battelle-Columbus Division 505 King Avenue

Columbus, $\mathrm{OH} 43201$

V. J. Flanigan

Univ. of Missouri-Rolla

223 Engineering Research Lab.

Rolla, MO 65401

P. Fox

Pacific Northwest and Alaska Regional Biomass Energy Program

Bonneville Power Administration 905 11th Avenue, NE

Portland, OR 97208

5 S. Friedrich

Biofuels and Municipal Waste

Technology Division

U.S. Department of Energy

Forrestal Building (CE-341)

1000 Independence Avenue

Washington, D.C. 20585

B. Goodman

Solar Fuels Division

Solar Energy Research Institute

1617 Cole Blvd.

Golden, CO 80401

M. S. Graboski

Syngas Systems Inc.

P.0. Box 757

Golden, CO 80402-0757 
No. of

Copies

W. D. Hunter

Energy Techno1ogy Department Weyerhaeuser Company

WTC-1B-30

Tacoma, WA 98477

J. D. Kerstetter

Washington State Energy Office

State of Washington

809 Legion Way S.E. ER-11

Olympia, WA 98504-1211

D. L. Klass

Institute of Gas Technology

IIT Center

3424 South State Street

Chicago, IL 60616

F. Kuzel

Council of Great Lakes

Governors

310 South Michigan Ave., SW

Chicago, IL 60604

\section{J. Lazar}

Engineering Division

Building 207

Argonne National Laboratory

9700 South Cass Avenue

Argonne, IL 60439

R. R. Loose

Director, Office of Renewable Energy Technologies

U.S. Department of Energy

Forrestal Building (CE-34)

1000 Independence Avenue

Washington, D.C. 20585

P. D. Mathusa

Program Director

New York State Energy Research and Development Authority

2 Rockefel ler Plaza

Albany, NY 12223
No. of

$\underline{\text { Copies }}$

T. R. Miles

Consulting Design Engineers

5475 S.W. Arrowwood Lane

Portland, OR 97225

R. A. O'Connell

CONEG Policy Research Center, Inc.

400 N. Capital Street, NW

Washington, DC 20001

M. Onischak

Institute of Gas Technology

IIT Center

3424 South State Street

Chicago, IL 60616

5 M. Paisley

Battelle-Columbus Division

505 King Avenue

Columbus, $\mathrm{OH} 43201$

G. Simons

California Energy Commission

1516 - 9th Street, MS-43

Sacramento, CA 95814

S. Sobczynski

Division of Improved Energy Productivity

U.S. Department of Energy

Forrestal Building CE-142

1000 Independence Avenue

Washington, DC 20585

D. J. Stevens

Solar Fuels Division

Solar Energy Research Institute

1617 Cole Blvd.

Golden, CO 80401

D. R. Swanson

Western Regional Biomass Energy Program

Western Area Power

Administration

1627 Cole Blvd., Bldg. A-147

Golden, CO 80401 
No. of

Copies

C. E. Taylor

Corporate Energy \& Env. Mgr.

Louisiana-Pacific Corporation

P.O. Box 158

Samoa, CA 95564

D. Taylor

Battelle-Columbus Division

505 King Avenue

Columbus, OH 43201

T. L. Tewksbury

Battelle-Columbus Division

505 King Avenue

Columbus, OH 43201

C. J. Wallace

Sol ar Energy Research

Institute

5109 Leesburg Pike, Suite 414

Falls Church, VA 22041

D. K. Walter

Biofuels and Municipal Waste Technology Division

U.S. Department of Energy

Forrestal Building (CE-341)

1000 Independence Avenue

Washington, D.C. 20585

E. I. Wan

Science Applications

International Corporation

1710 Goodridge Drive

McLean, VA 22102

C. Willey

State of Maryland Envi ronmental Service

2020 Industrial Dr.

Annapolis, MD 21401

E. Wood

Energetics, Inc.

9210 Route 108

Columbia, MD 21045
No. of

Copies

FOREIGN

A. V. Bridgwater

The University of Aston in

Bi rmingham

Dept. of Chemical Engineering

Gosta Green

Birmingham

ENGLAND B4 7ET

\section{ONSITE}

\section{DOE Richland}

Operations Office

E. C. Norman

14 Pacific Northwest Laboratory

M. A. Gerber

G. F. Schiefelbein (6)

L. J. Sealock

Publishing Coordination

Technical Report Files (5) 
